\title{
Comparison of Reduced-Intensity and Myeloablative Conditioning Regimens for Allogeneic Hematopoietic Stem Cell Transplantation in Patients with Acute Myeloid Leukemia and Acute Lymphoblastic Leukemia: A Meta-Analysis
}

\author{
S. Fadilah Abdul Wahid, ${ }^{1}$ Nor-Azimah Ismail, ${ }^{1}$ Mohd-Razif Mohd-Idris, ${ }^{1}$ Fariza Wan Jamaluddin, \\ NorRafeah Tumian, ${ }^{1}$ Ernie Yap Sze-Wei, ${ }^{1}$ Norasiah Muhammad, ${ }^{2}$ and Ming Lai Nai ${ }^{3}$
}

Currently, the indications to perform reduced-intensity conditioning allogeneic hematopoietic stem cell transplant (RIC-HCT) are based on data derived mainly from large registry and single-centre retrospective studies. Thus, at the present time, there is limited direct evidence supporting the current practice in selecting patients with acute myeloid leukemia (AML) and acute lymphoblastic leukemia (ALL) for RIC versus myeloablative conditioning (MAC) transplants. To determine the relationship between dose intensity of conditioning regimen and survival outcomes after allografting in AML/ALL patients, we performed a meta-analysis of 23 clinical trials reported between 1990 and 2013 involving 15,258 adult patients that compare survival outcomes after RIC-HCT versus MAC-HCT. RIC-HCT resulted in comparable <2-year and 2-6 year overall survival (OS) rates post-transplantation even though the RIC-HCT recipients were older and had more active disease than MAC-HCT recipients. The 2-6 year progression-free survival (PFS), nonrelapse mortality, acute graftversus-host disease $(\mathrm{G} v \mathrm{HD})$ and chronic $\mathrm{G} v \mathrm{HD}$ rates were reduced after RIC-HCT, but relapse rate was increased. Similar outcomes were observed regardless of disease type and status at transplantation. Odds ratio for all outcomes remained comparable with or without performing separate analyses for the year of HCT and for retrospective versus prospective studies. Among RIC-HCT recipients, survival rates were superior if patients were in CR at transplantation. Significant inter-study heterogeneity for aGvHD data and publication bias for PFS data were observed. This meta-analysis showed no OS benefit of MAC-HCT over RIC-HCT across the entire cohort of patients suggesting that RIC-HCT could be an effective therapeutic option for AML/ALL patients who are ineligible for MAC-HCT and CR status is preferred before RIC-HCT.

\section{Introduction}

$\mathrm{S}$ EVERAL INVESTIGATORS HAVE reported a dose-response $\checkmark$ relationship between the pretransplant conditioning regimen and long-term outcome after allogeneic hematopoietic transplant (HCT) in acute leukemia [1,2]. More intensive conditioning regimen is associated with a reduced risk of relapse after HCT, but does not translate in improvement of survival due to increased treatment-related mortality (TRM) and nonrelapse mortality (NRM) [3]. Reduced intensity conditioning (RIC)-HCT through graft-versus-leukemia (GvL) effect may provide previously unavailable opportunities to cure leukemia without the morbidity and mortality associated with conventional myeloablative conditioning (MAC)-HCT [4-6]. The balance between the increased anti-leukemia efficacy of allogeneic HCT and the risk of NRM depends on the disease risk category and recipients' physical fitness and source of the transplanted stem cell [7]. The best insight into the impact of intensity of conditioning regimen on survival outcomes from acute myeloid leukemia (AML) and acute lymphoblastic leukemia (ALL) patients derives from the retrospective analysis of large registries [8-12]. These studies showed that RIC has been associated with lower TRM, but higher relapse rates (RR) leading to similar overall survival (OS) when compared to MAC-HCT.

\footnotetext{
${ }^{1}$ Cell Therapy Center, Faculty of Medicine, Universiti Kebangsaan Malaysia Medical Centre, Kuala Lumpur, Malaysia.

${ }^{2}$ Department of Epidemiology and Biostatistic, Institute for Medical Research, Kuala Lumpur, Malaysia.

${ }^{3}$ Pediatric and Child Health Research Group, Department of Pediatrics, Faculty of Medicine, University of Malaya Medical Centre, Kuala Lumpur, Malaysia.
} 
However, due to either small numbers of patient or heterogeneity of patient population (age, comorbidity, stage of disease) and conditioning regimens, it is not possible to draw a definitive conclusion and formulate treatment recommendation from these studies. In fact, it is quite possible that with the elimination of patient selection bias, RIC-HCT may be superior to MAC-HCT [13].

Currently, the indications to perform RIC-HCT are based on the literature review and expert consensus that are mainly derived from large registry survey analyses and retrospective studies, including mostly nonrandomized, single-centre, and short-term studies. Thus, at the present time, there is limited direct evidence supporting the current practice in selecting patients with AML and ALL for RIC versus MAC conditioning regimens.

To better address the important question on whether the type and intensity of conditioning regimen used for AML/ ALL affects survival and other key transplant outcomes, we undertook a meta-analysis of all studies that compared RICHCT and MAC-HCT. To the best of our knowledge there has been no published meta-analysis that provides comprehensive estimates of transplant outcomes among AML/ALL patients receiving RIC versus MAC allogeneic transplants.

\section{Methods}

\section{Search strategy}

We searched MEDLINE, EMBASE (from 1950 to present), CENTRAL, and CIBMTR registries using the following terms and boolean operators: "stem cell transplantation," "preparative regimen OR conditioning," AND "reduced conditioning OR nonmyeloablative conditioning OR reduced toxicity regimen," AND “acute leukemia OR acute myeloid leukemia OR acute lymphoblastic leukemia." We limited the publication type to comparative clinical trials. We screened the titles, abstracts, and then the reference list to identify eligible studies.

\section{Study selection}

We included all published clinical trials of adult patients with AML and ALL that compared RIC-HCT versus MACHCT regimens with survival outcomes, without any restriction on the language used and the year of publication. When multiple articles were reported on the study, the most updated data were analyzed.

Outcomes. Primary outcomes included all survival rates as defined by standard definitions and evaluation of endpoints following stem cell transplantation [14].

OS was defined as the time from transplantation until death from any cause. Progression-free survival (PFS) was defined as the probability of being alive with no indication of disease progression. Disease-free survival (DFS) was defined as survival without morphological evidence of relapse or progression of disease. Leukemia-free survival (LFS) was calculated from the date of first CR until the date of relapse or death from any cause. PFS, DFS, and LFS data was pooled to estimate the overall treatment effect and presented in the result section as PFS. Secondary outcomes included, NRM, RR, and acute and chronic graft-versus-host disease $(\mathrm{G} v \mathrm{HD})$. NRM was defined as any death with no evidence of disease relapse or progression, including death due to treatment (TRM).

\section{Data extraction and synthesis}

Three authors (S.F.A.W., N.I., M.R.I) independently extracted the data from the included studies using a prepiloted data collection form. The data collected included the study setting and year, participant characteristics, intervention, comparison and outcomes. Any disagreement among the authors was discussed leading to a consensus. Meta-analysis was performed using the RevMan 5.2. Pooled estimates of treatment effects on outcomes were calculated as odds ratio (OR) and their $95 \%$ confidence intervals (CIs), using a fixed effect model. We used Forest plot to graphically display the pooled results.

The $I^{2}$ statistic was used to assess statistical heterogeneity, with $I^{2}>50 \%$ as cut-off to indicate substantial heterogeneity. If we found substantial heterogeneity, we explored possible causes, including patient characteristics, transplant regimen, co-intervention, and outcome measurements.

We constructed funnel plots to screen for publication bias for all clinical outcomes. If significant asymmetry was found in the funnel plot, we would include a note of caution in our results.

Additionally, we presented standard descriptive statistics on patient, disease, and transplant characteristics which were analyzed using the SPSS version 19 . A $P$-value below 0.05 was considered statistically significant.

\section{Results}

\section{Trial searches/selection}

Initial searches yielded 1,306 articles. No additional trials were identified from recent review articles [13,15-21]. After screening, 1,278 articles were excluded on the basis of relevance, design, appropriate outcome data, and duplicate publications (Fig. 1). A further 252 articles were excluded because they included all patients with hematologic malignancies and did not perform separate analysis on patients with AML and ALL. Three studies [22-24] that compared reduced toxicity conditioning (RTC) regimen consisting of myeloablative doses of busulfan in combination with fludarabine and conventional MAC regimen were excluded from the meta-analysis. Two studies $[25,26]$ were excluded as they limited RIC regimens to patients aged above 50 years and MAC regimens to younger patients. In addition, these studies had discriminated the source of donor cells used for transplantation; MAC group received either BM cells [25] or CD34-positive peripheral blood stem cells (PBSC) [26] whereas RIC group received unselected PBSC [25,26]. Finally, 23 clinical trials (22 retrospective studies and 1 prospective open-label randomized phase 3 study [7]) conducted and published between 1990 and 2013 that compared the survival outcomes of RIC-HCT and MAC-HCT were selected. There were 11, 5, 5, 2 studies involving AML + MDS, AML only, ALL only, AML/ALL patients, respectively, and one study involving all 3 diseases. The median follow-up period of the included studies was 36 months (range; 1-166). Selected and excluded clinical trial details are shown in Tables 1 and 2, respectively. 


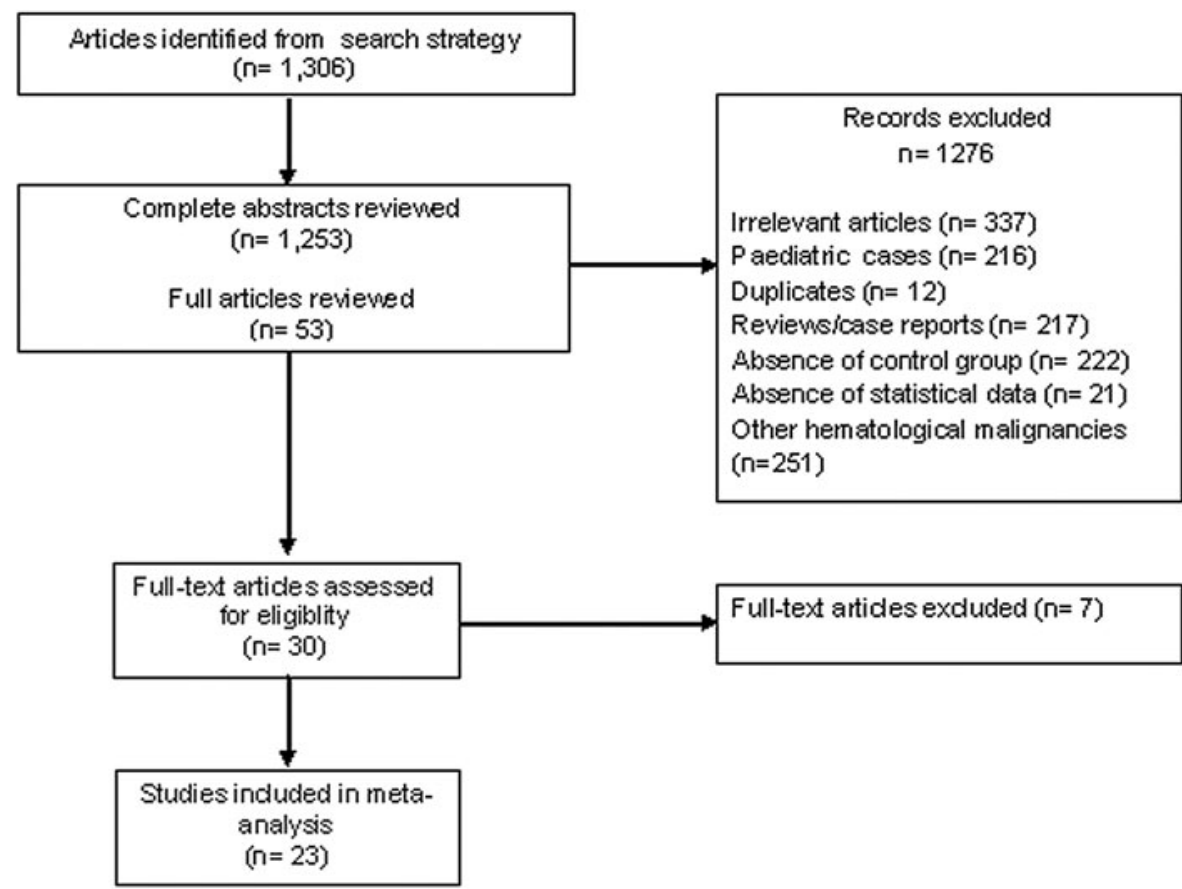

FIG. 1. Flow diagram for study searches and selection process.

\section{Patient, disease, and transplant characteristics}

The meta-analysis included 14,664 adult patients and approximately one third of patients received RIC-HCT. RIC-HCT recipients were significantly older than MACHCT recipients (Table 3). Compared to MAC-HCT, fewer RIC-HCT recipients were transplanted in CR1 and more patients received PB stem cells from related donors. There were no significant differences in cytogenetic risk and performance status at transplantation between the two transplant groups.

The dose intensity of conditioning regimen was defined according to established criteria $[27,28]$. The type of RIC regimens ranged from low-dose total body irradiation (TBI) plus immunosuppressive agents and nonmyeloablative doses of one or two alkylating agents, whereas the MAC regimens consisted of high doses of TBI plus myeloablative doses of alkylating agent. In the RIC group, the most common regimens were $90-160 \mathrm{mg} / \mathrm{m}^{2}$ IV fludarabine plus either 6$9 \mathrm{mg} / \mathrm{kg}$ oral busulfan (or equivalent dose of IV busulfan) $(40 \%)$, or $2-8$ Gy TBI $(26 \%)$, or $80-140 \mathrm{mg} / \mathrm{m}^{2}$ IV melphalan $(13 \%)$, or $5-10 \mathrm{mg} / \mathrm{kg}$ IV thiotepa with or without antithymocyte globulin (ATG). The conventional MAC regimens were mainly composed of $120 \mathrm{mg} / \mathrm{kg}$ IV cyclophosphamide plus either $\geq 12$ Gy TBI $(62 \%)$ or $16 \mathrm{mg} / \mathrm{kg}$ PO busulfan or $12.8 \mathrm{mg} / \mathrm{kg}$ IV busulfan (24\%) (Table 1).

\section{Meta-analysis of clinical outcomes}

We reported PFS, OS, NRM, and RR for the entire cohort of patients in two subgroups: (1) $\leq 2$-year, (2) > 2-year (between 2 and 6 years). We performed subgroup analyses for these outcomes according to the diagnosis (AML + MDS or ALL), remission status at the time of transplantation (CR versus non-CR), age of patient, and the timing/year of HCT (patients who had received HCT before year 2000 (1990'sHCT) versus those who had received HCT at/after year 2000 (2000's-HCT)).
Table 4 lists the $P$-values for transplant outcomes reported by the individual trials. Tables 5 and 6 summarizes the OR for the transplant outcomes derived from this meta-analysis. OR values for all transplant outcomes were also derived by performing a separate analysis of the retrospective studies versus the randomized controlled trial (RCT) [7].

\section{Progression-free survival}

Entire cohort of patients. Nineteen out of 23 trials involving 12,510 patients reported PFS for a period of $1-6$ years after HCT. Ten trials reported data for $\leq 2$-year PFS, whereas 10 studies reported data for $>2$-year PFS (one trial reported both $\leq 2$-year PFS and $>2$-year PFS [29] (Table 4). The individual trials showed no differences in PFS between RIC-HCT and MAC-HCT for $\leq 2$-year and > 2-year PFS rates. The pooled estimates from 10 studies showed that the $\leq 2$-year PFS rates were comparable between RIC-HCT and MAC-HCT groups (Table 5 and Fig. 2a).

Pooled estimates from 10 trials indicated that the $>2$-year PFS was significantly lower in RIC-HCT than MAC-HCT recipients. The PFS rate was higher after MAC-HCT in patients aged below 50 years.

Of note, there was no significant change in OR for PFS and other transplant outcomes even after a separate analysis was performed for retrospective studies versus RCT. There was no substantial heterogeneity among the included studies for all analyses under this group of outcome $\left(I^{2}, 0 \%-40 \%\right)$.

AML plus MDS or ALL. The subgroup analysis of PFS included 7,817 patients with AML + MDS from 11 trials and 2,970 patients with ALL from 5 trials. Among patients with AML + MDS and ALL, MAC-HCT led to higher PFS than RIC-HCT, which was probably due to superior $>2$-year PFS. There was no difference in $\leq 2$-year PFS between the two groups.

CR1 or non-CR1. Approximately $61 \%(3,217)$ of patients were transplanted in CR1 and one third of these patients 


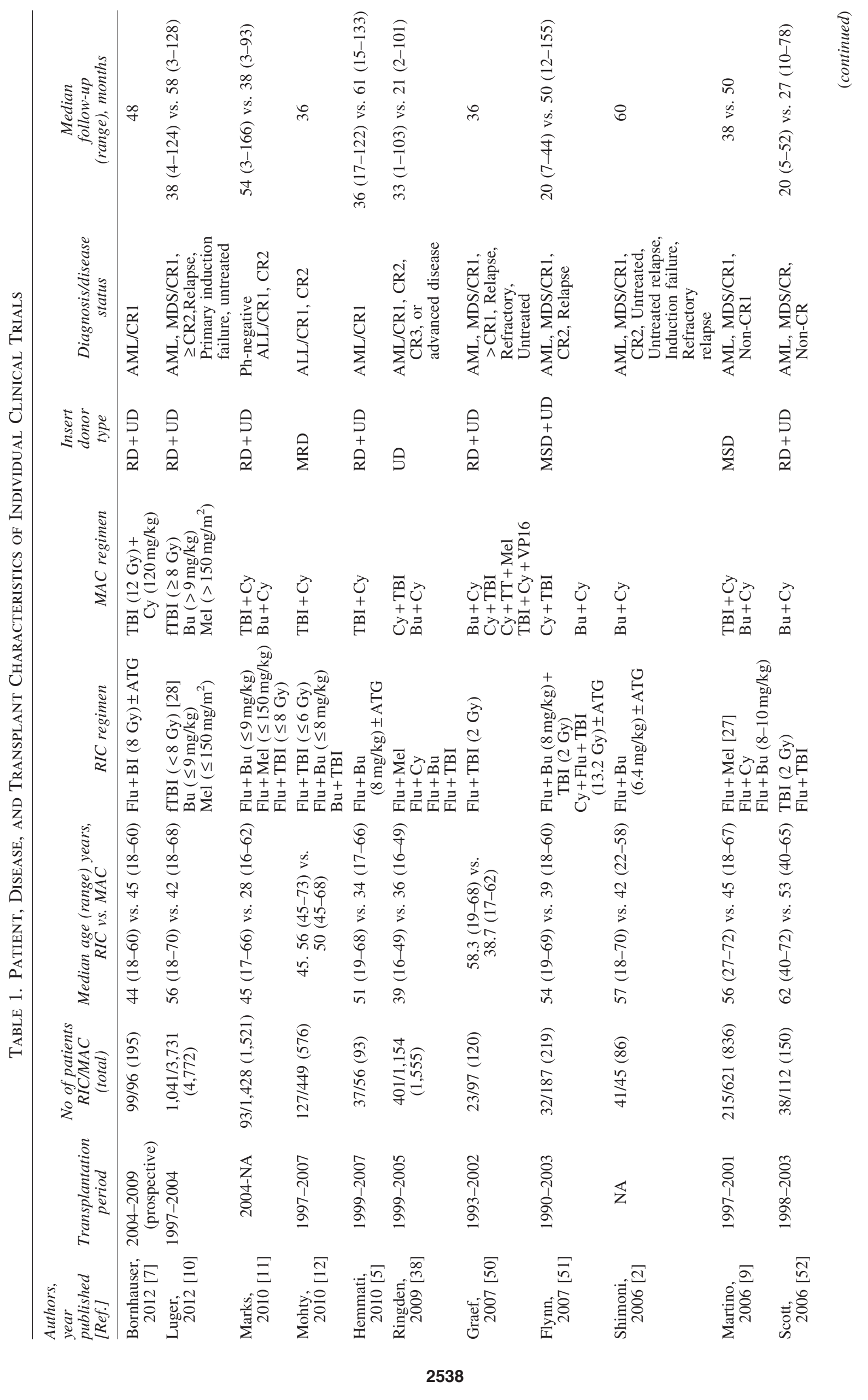




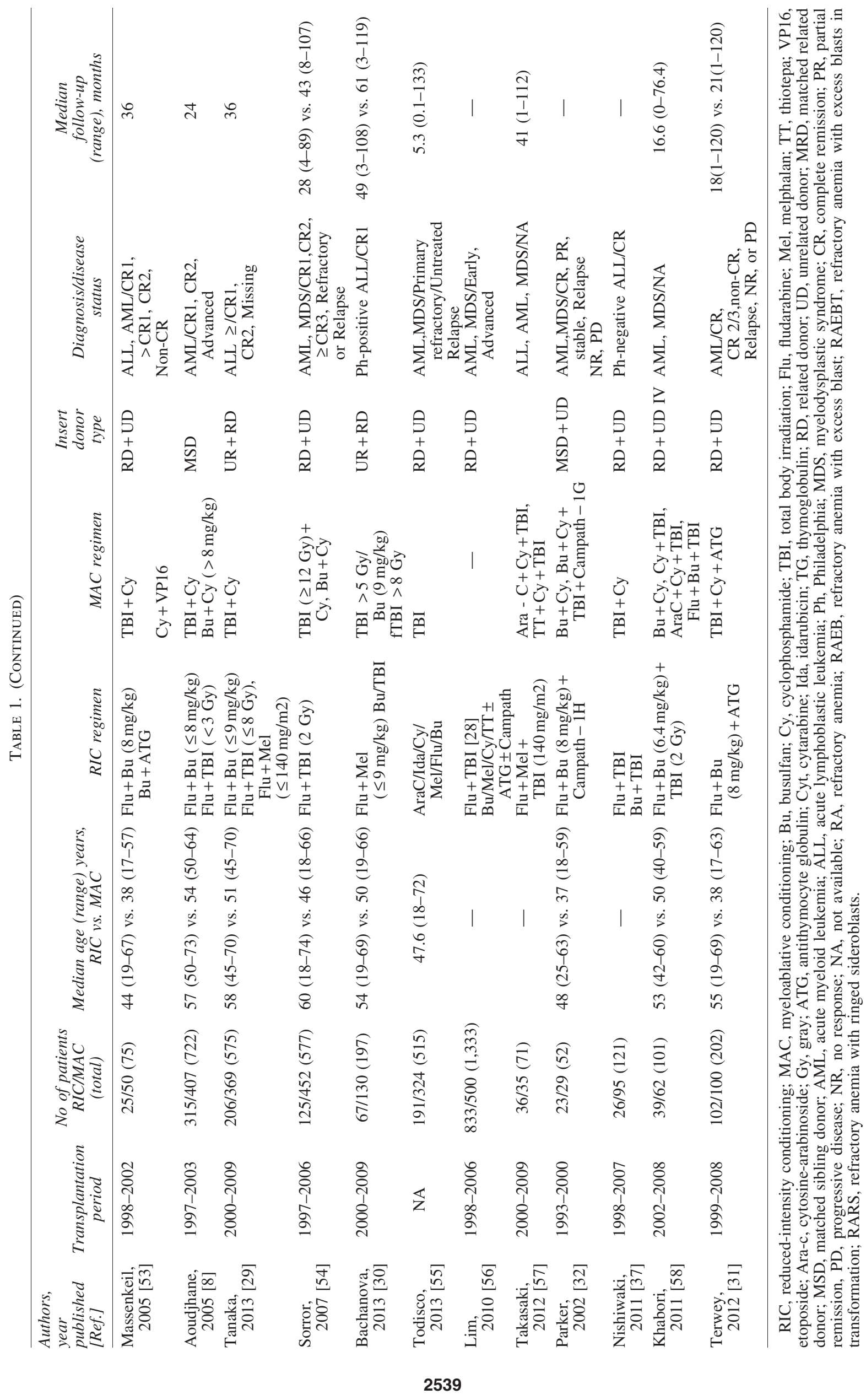


Table 2. Characteristics of Excluded Studies

Authors, year

published [Ref.]

Andersson, 2008 [22]

Goker, 2013 [23]

Raida, 2011 [24]

Lioure, 2012 [25]

Martino, 2008 [26]

Martino, 2013 [59]

Foran, 2013 [60]
Reason for exclusion

This study compared reduced toxicity conditioning (RTC) regimen consisting of myeloablative doses of busulfan in combination with fludarabine and conventional MAC regimen.

This study administered myeloablative doses of busulfan (total intravenous busulfan $12.8 \mathrm{mg} / \mathrm{kg}$ ) in combination with fludarabine (Flu/Bu/ATG) to $60 \%$ of the patients in the RIC transplant group.

This study compared RTC regimen consisting of myeloablative doses of busulfan in combination with fludarabine and conventional MAC regimen.

This study limited RIC regimens to patients aged above 50 years and MAC regimens to younger patients. This study also discriminated the source of cells used for transplantation; bone marrow cells to MAC group, and unselected peripheral blood stem cells (PBSC) to RIC group.

This study limited RIC regimens to patients aged above 50 years and MAC regimens to younger patients. This study also discriminated the source of cells used for transplantation; CD34-positive selected cells to MAC group, and unselected PBSC to RIC group.

This study presented long-term survival outcomes (Overall survival and progression-free survival at 7-year posttransplantation) whereas the other potentially eligible studies presented survival outcomes below 6 years posttransplantation.

Moreover, this study included patients transplanted before 2005 (total patients 878) that has been mostly included in Martino 2006 (total patients 868).

This study included patients under the age of 13 years old. received RIC-HCT. The overall estimate showed a higher PFS in CR1 patients who received MAC-HCT than RICHCT (Table 5). The sub-analysis showed that MAC-HCT resulted in a superior PFS in AML patients transplanted in CR1, which was attributed to a better $>2$-year PFS in the MAC-HCT cohort. ALL patients transplanted in CR $(\mathrm{CR} 1+\mathrm{CR} 2)$ showed comparable PFS rate between RIC-
HCT and MAC-HCT [33.5\% vs. 40.6\%, OR:0.78 (0.551.10), $P=0.15]$

Patients transplanted in non-CR1 had a comparable PFS rate after RIC-HCT and MAC-HCT. Similarly, the PFS was comparable between the two transplant groups if we included only patients with AML transplanted in non-CR1. Among the RIC recipients, the PFS rate was significantly

Table 3. Summary of Patients, Disease, and Transplant Characteristics of all Included Clinical Trials

\begin{tabular}{|c|c|c|c|c|}
\hline No. & Parameters & $R I C-H C T$ & $M A C-H C T$ & p-value \\
\hline & & No $(\%)$ & No $(\%)$ & \\
\hline 1 & No. of patients & $4,135(28.20)$ & $10,529(71.80)$ & 0.043 \\
\hline 2 & Median age at transplantation, years & $53(39-62)$ & $43(28-54)$ & 0.000 \\
\hline \multirow[t]{3}{*}{3} & Gender ${ }^{\mathrm{a}}$ & & & \\
\hline & Male & $1,850(56.35)$ & $4,726(54.15)$ & 0.03 \\
\hline & Female & $1,433(43.65)$ & $4,002(45.85)$ & 0.03 \\
\hline \multirow[t]{3}{*}{4} & Type of disease $\mathrm{a}^{\mathrm{a}}$ & & & \\
\hline & AML/MDS only & $2,838(84.31)$ & $7,803(75.82)$ & 0.0004 \\
\hline & ALL only & $528(15.69)$ & $2,489(24.18)$ & 1.00 \\
\hline \multirow[t]{3}{*}{5} & Status of disease ${ }^{\mathrm{a}}$ & & & \\
\hline & CR & $1,538(37.23)$ & $4,046(43.56)$ & $<0.0001$ \\
\hline & Non-CR/active disease & $2,593(62.77)$ & $5,243(56.44)$ & 0.0005 \\
\hline \multirow[t]{4}{*}{6} & Cytogenetics $^{\mathrm{a}}$ & & & \\
\hline & Good & $168(8.30)$ & $1,017(15.27)$ & 0.19 \\
\hline & Intermediate & $1,222(60.35)$ & $3,956(59.37)$ & 0.49 \\
\hline & Poor & $635(31.35)$ & $1,690(25.36)$ & 0.11 \\
\hline \multirow[t]{3}{*}{7} & Karnofsky score ${ }^{\mathrm{a}}$ & & & \\
\hline & $\geq 90 \%$ & $429(33.97)$ & $1,475(27.79)$ & 0.48 \\
\hline & $<90 \%$ & $834(66.03)$ & $3,832(72.21)$ & 0.48 \\
\hline \multirow[t]{2}{*}{8} & Stem cell source ${ }^{\mathrm{a}}$ & & & \\
\hline & Peripheral blood stem cells & $2,339(78.78)$ & $4,945(52.57)$ & $<0.00001$ \\
\hline \multirow[t]{5}{*}{9} & Donor type $^{\mathrm{a}}$ & & & \\
\hline & Matched related donor & $1,337(66.19)$ & $4,077(65.35)$ & 0.02 \\
\hline & Matched unrelated donor & $566(28.02)$ & $1,675(26.85)$ & $<0.00001$ \\
\hline & Related donor & $1,452(47.92)$ & $4,607(48.23)$ & $<0.00001$ \\
\hline & Matched donor & $4,020(88.92)$ & $4,906(72.57)$ & $<0.00001$ \\
\hline
\end{tabular}

${ }^{\mathrm{a}}$ Data not available for all patients.

HCT, hematopoietic stem cell transplantation. 
Table 4. Summary of P-Value for Transplant Outcomes Between RIC-HCT and MAC-HCT ObTained From the Individual Clinical Trials

\begin{tabular}{|c|c|c|c|c|c|c|c|c|c|c|}
\hline \multirow{2}{*}{$\begin{array}{l}\text { Transplant } \\
\text { outcome }\end{array}$} & \multicolumn{2}{|c|}{$P F S / D F S / L F S$} & \multicolumn{2}{|c|}{$O S$} & \multicolumn{2}{|c|}{$N R M / T R M$} & \multirow{2}{*}{$\frac{a G v H D}{I I-I V}$} & \multirow[b]{2}{*}{$c G v H D$} & \multicolumn{2}{|c|}{ Relapse } \\
\hline & $\leq 2$-year & $>2$-year & $\leq 2$-year & $>2$-year & $\leq 2$-year & $>2$-year & & & $\leq 2$-year & $>2-y e a r$ \\
\hline \multicolumn{11}{|l|}{ Author } \\
\hline Bornhauser [7] & - & 0.4 & ns & - & - & $<0.05^{\mathrm{a}}$ & ns & ns & ns & - \\
\hline uger [10] & - & 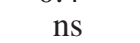 & - & ns & - & $\mathrm{ns}$ & $<0.001^{\mathrm{a}}$ & 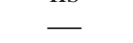 & $<0.001^{\mathrm{a}}$ & - \\
\hline Marks [11] & - & 0.1 & - & 0.3 & 0.6 & 0.8 & 0.1 & 0.1 & 0.1 & 0.08 \\
\hline Mohty [12] & 0.07 & - & 0.5 & - & $<0.05^{\mathrm{a}}$ & - & 0.2 & 0.5 & $<0.001^{\mathrm{a}}$ & - \\
\hline 'Hemmati [5] & 0.9 & - & 0.8 & - & $<0.05^{\mathrm{a}}$ & - & $<0.01^{\mathrm{a}}$ & $\mathrm{ns}$ & 0.8 & - \\
\hline Ringden [38] & 0.2 & - & - & - & 0.4 & - & 0.2 & ns & $<0.05^{\mathrm{a}}$ & - \\
\hline Graef [50] & 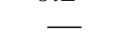 & 0.1 & - & - & - & 0.9 & $<0.05^{\mathrm{a}}$ & 0.07 & - & $<0.01^{\mathrm{a}}$ \\
\hline Flyn & 0.4 & - & - & 0.5 & - & - & 0.4 & 0.4 & $<0.05^{\mathrm{a}}$ & - \\
\hline Shimoni [2] & ns & - & ns & - & 0.05 & - & $<0.05^{\mathrm{a}}$ & $<0.05$ & ns & - \\
\hline Mar & - & 0.1 & - & 0.7 & - & $<0.05^{\mathrm{a}}$ & $<0.001^{\mathrm{a}}$ & 0.1 & - & $<0.01^{\mathrm{a}}$ \\
\hline Scott [52] & - & 0.1 & - & 0.5 & - & 0.9 & ns & ns & - & - \\
\hline eil [53] & - & 0.2 & - & 0.9 & - & $<0.05^{\mathrm{a}}$ & ns & $\mathrm{ns}$ & & ns \\
\hline Aoudjhane [8] & 0.8 & - & 0.4 & - & $<0.001^{\mathrm{a}}$ & - & $<0.01^{\mathrm{a}}$ & 0.6 & $<0.001^{\mathrm{a}}$ & - \\
\hline & & 0.09 & 0.6 & 0.7 & 0.2 & 0.6 & 0.3 & 0.7 & 0.6 & $<0.01^{\mathrm{a}}$ \\
\hline Sorro & 0.7 & - & 0.7 & - & 0.1 & - & - & - & 0.05 & - \\
\hline Bacha & - & 0.7 & - & 0.6 & $<0.001^{\mathrm{a}}$ & - & $<0.01^{\mathrm{a}}$ & 0.1 & - & 0.05 \\
\hline Todis & - & - & ns & - & ns & - & - & - & $\mathrm{ns}$ & - \\
\hline Lim & - & - & - & 0.7 & - & $0.05^{\mathrm{a}}$ & - & - & - & $<0.01^{\mathrm{a}}$ \\
\hline Takasaki [57] & - & - & - & 0.6 & - & 0.2 & ns & - & - & 0.1 \\
\hline Parker & $\mathrm{ns}$ & - & ns & - & ns & - & $<0.01^{\mathrm{a}}$ & $<0.01$ & $\mathrm{~ns}$ & - \\
\hline ki [37] & 0.9 & - & 0.8 & - & 0.7 & - & - & - & 0.2 & - \\
\hline Khabc & - & - & - & 0.5 & - & 0.5 & ns & ns & - & 0.6 \\
\hline Terwey [31] & - & ns & - & ns & - & ns & $<0.001^{\mathrm{a}}$ & $\mathrm{ns}$ & - & ns \\
\hline
\end{tabular}

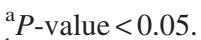

${ }^{\mathrm{b}}$ Raw data not counted for aGvHD and $\mathrm{cG} v \mathrm{HD}$ analysis as the patients in Hemmati PG [5] were the same as patients included in Terwey TH [31] for acute and chronic GvHD outcomes.

OS, overall survival; PFS, progression-free survival; DFS, disease-free survival; LFS, leukemia-free survival; NRM, nonrelapsed mortality; TRM, treatment-related mortality; $\mathrm{aG} v \mathrm{HD}$, acute graft-versus-host disease; cGvHD, chronic graft-versus-host disease; ns, not significant.
}

higher in AML patients transplanted in CR1 compared to patients transplanted in non-CR1 (42.3\% vs. $30.4 \%$, $P<0.01)$.

Transplant performed in 2000's or in 1990's. The subanalysis of PFS involving studies that only included patients who had received HCT in the 2000's (2,554 patients) and studies that included patients who had received HCT in the 1990's (9,956 patients) showed that the PFS rate was higher after MAC-HCT than in RIC-HCT (2000's: $41.9 \%$ vs. $39.8 \%, P<0.05$; 1990 's: $37.8 \%$ vs. $34.4 \%, P<0.0005$ ) (Table 5).

\section{Overall survival}

Entire cohort of patients. OS were reported in 22 trials and 12,983 patients during 1-6 year follow-up period. Ten trials reported data for $\leq 2$-year OS, whereas 12 trials reported data for $>2$-year OS. All individual studies showed comparable OS rates between RIC and MAC transplants (Table 4). Pooled estimate from all 22 trials showed that the $\leq 2$ year OS and >2-year OS rates were comparable between the RIC-HCT and MAC-HCT recipients (Table 5 and Fig. 2b). OS rates were comparable after RIC-HCT and MACHCT regardless of recipients' age (above or below 50 years). There was no substantial heterogeneity among the included studies for all analyses under this group of outcomes $\left(I^{2}, 0 \%-19 \%\right)$.
$A M L+M D S$ or $A L L$. The sub-analysis of OS included 9,754 patients with AML + MDS from 13 trials and 2,990 patients with ALL from 5 trials. The pooled analysis of 13 trials showed that the OS was comparable in AML+MDS patients receiving either RIC or MAC transplants. Additionally, the $\leq 2$-year and $>2$-year OS rates were equivalent between the two transplant groups.

The pooled analysis of five trials showed that the OS was comparable in ALL patients receiving either RIC-HCT or MAC-HCT. Sub-analysis according to duration of OS posttransplant among ALL patients was not done due to inadequate data.

CR1 versus non-CR1. Nine trials reported OS for patients transplanted in CR1 (2,522 patients) and five reported OS for non-CR1 patients (2,233 patients). The pooled analysis of nine trials for patients transplanted in CR1 showed that patients who received RIC-HCT and MAC-HCT had comparable OS. Similarly, AML in CR1 and ALL in CR showed comparable OS between RIC-HCT and MAC-HCT. By contrast, in non-CR1 patients, RIC group had a higher OS. Among the RIC-HCT recipients, OS was significantly higher in AML patients transplanted in CR1 compared to non-CR1 (54.7\% vs. $33.8 \%, P<0.0002)$.

There was no significant inter-study heterogeneity for all analyses under this group of outcomes.

Transplant performed in 2000's or in 1990's. The subanalysis of OS involving studies that only included patients 
Table 5. Summary of Meta-Analysis of Survival Outcomes for RIC-HCT Versus MAC-HCT

\begin{tabular}{|c|c|c|c|c|c|c|c|}
\hline Primary outcomes & $\begin{array}{l}\text { No. of } \\
\text { studies }\end{array}$ & $\begin{array}{l}\text { No. of patient } \\
\text { RIC (yes/all) }\end{array}$ & $\begin{array}{l}\text { No. of patient } \\
\text { MAC (yes/all) }\end{array}$ & $\begin{array}{l}\text { Heterogeneity } \\
\qquad\left(I^{2}\right)\end{array}$ & $\begin{array}{c}O R \\
(95 \% C I)\end{array}$ & $\begin{array}{c}\text { OR } \\
\mathrm{P}-\text { value }\end{array}$ & $\begin{array}{c}\text { OR } \\
\mathrm{P} \text {-value }\end{array}$ \\
\hline \multicolumn{8}{|l|}{ PFS } \\
\hline$\leq 2$-year & 10 & $560 / 1,333$ & $1,443 / 3,237$ & $0 \%$ & $0.89(0.77,1.02)$ & 0.10 & 0.10 \\
\hline$>2$-year & 10 & $623 / 1,872$ & $2,461 / 6,643$ & $6 \%$ & $0.80(0.72,0.90)$ & 0.0001 & $<0.0001$ \\
\hline AML only & 11 & $725 / 2,018$ & $2,144 / 5,799$ & $20 \%$ & $0.86(0.77,0.96)$ & 0.005 & 0.003 \\
\hline ALL only & 5 & $183 / 518$ & $1,012 / 2,452$ & $0 \%$ & $0.76(0.61,0.93)$ & 0.009 & 0.009 \\
\hline AML $\leq 2$-year & 7 & $379 / 974$ & $999 / 2,324$ & $0 \%$ & $0.87(0.74,1.02)$ & 0.09 & 0.09 \\
\hline AML > 2-year & 7 & $497 / 1,507$ & $1,675 / 4,735$ & $27 \%$ & $0.82(0.72,0.93)$ & 0.002 & 0.002 \\
\hline CR1 & 9 & $348 / 885$ & $1,078 / 2,332$ & $0 \%$ & $0.74(0.62,0.87)$ & 0.0004 & 0.0002 \\
\hline Non-CR1 & 5 & $163 / 714$ & $368 / 1,326$ & $40 \%$ & $1.00(0.78,1.29)$ & 0.97 & 0.97 \\
\hline CR1 \& AML & 6 & $251 / 593$ & $612 / 1,296$ & $0 \%$ & $0.73(0.60,0.90)$ & 0.003 & 0.001 \\
\hline Non-CR1 \& AML & 3 & $51 / 168$ & $80 / 255$ & $23 \%$ & $0.88(0.56,1.38)$ & 0.58 & 0.58 \\
\hline $\mathrm{CR} 1+\mathrm{CR} 2 \& \mathrm{ALL}$ & 3 & $62 / 185$ & $668 / 1,634$ & $0 \%$ & $0.78(0.55,1.10)$ & 0.15 & 0.15 \\
\hline$\geq 50$ year $^{b}$ & 6 & $404 / 1,005$ & $713 / 1,649$ & $0 \%$ & $0.89(0.75,1.05)$ & 0.17 & 0.17 \\
\hline$<50$ year $^{\mathrm{c}}$ & 5 & $161 / 388$ & $1,087 / 2,550$ & $0 \%$ & $0.77(0.61,0.97)$ & 0.03 & 0.01 \\
\hline 2000 's & 5 & $201 / 505$ & $860 / 2,049$ & $0 \%$ & $0.78(0.63,0.98)$ & 0.03 & 0.02 \\
\hline 1990 's & 14 & $858 / 2,494$ & $2,826 / 7,462$ & $0 \%$ & $0.83(0.75,0.91)$ & 0.0002 & 0.0002 \\
\hline \multicolumn{8}{|l|}{ OS } \\
\hline$\leq 2$-year & 9 & $488 / 932$ & $1,066 / 2,083$ & $0 \%$ & $1.00(0.85,1.17)$ & 0.98 & 0.98 \\
\hline$>2$-year & 13 & $1,072 / 2,985$ & $2,933 / 7,558$ & $0 \%$ & $0.97(0.88,1.07)$ & 0.57 & 0.52 \\
\hline AML only & 13 & $1,118 / 3,094$ & $2,468 / 6,660$ & $0 \%$ & $0.96(0.87,1.06)$ & 0.40 & 0.36 \\
\hline ALL only & 5 & $254 / 519$ & $1,219 / 2,471$ & $0 \%$ & $1.03(0.84,1.26)$ & 0.76 & 0.76 \\
\hline AML $\leq 2$-year & 6 & $273 / 573$ & $568 / 1,170$ & $0 \%$ & $0.93(0.75,1.15)$ & 0.50 & 0.50 \\
\hline AML > 2-year & 9 & $879 / 2,583$ & $1,957 / 5,596$ & $0 \%$ & $0.97(0.87,1.08)$ & 0.54 & 0.50 \\
\hline CR1 & 9 & $364 / 710$ & $897 / 1,812$ & $0 \%$ & $0.99(0.81,1.20)$ & 0.89 & 0.79 \\
\hline Non-CR1 & 5 & $256 / 759$ & $450 / 1,474$ & $19 \%$ & $1.30(1.05,1.62)$ & $0.02^{\mathrm{a}}$ & 0.02 \\
\hline CR1 \& AML & 6 & $249 / 455$ & $426 / 832$ & $0 \%$ & $0.97(0.77,1.24)$ & 0.84 & 0.70 \\
\hline Non-CR1 \& AML & 3 & $77 / 213$ & $130 / 403$ & $0 \%$ & $1.13(0.77,1.64)$ & 0.54 & 0.54 \\
\hline $\mathrm{CR} 1+\mathrm{CR} 2 \& \mathrm{ALL}$ & 3 & $138 / 292$ & $502 / 1,036$ & $0 \%$ & $1.04(0.77,1.40)$ & 0.79 & 0.79 \\
\hline$\geq 50$ year $^{b}$ & 8 & $658 / 1,661$ & $871 / 2,064$ & $0 \%$ & $1.06(0.62,1.22)$ & 0.42 & 0.42 \\
\hline$<50$ year $^{\mathrm{c}}$ & 5 & $154 / 431$ & $871 / 1,921$ & $0 \%$ & $0.91(0.70,1.18)$ & 0.46 & 0.33 \\
\hline 2000 's & 8 & $323 / 772$ & $1,140 / 2,489$ & $0 \%$ & $1.00(0.83,1.20)$ & 0.96 & 0.87 \\
\hline 1990 's & 13 & $1,099 / 2,939$ & $2,619 / 6,783$ & $0 \%$ & $0.97(0.88,1.06)$ & 0.49 & 0.49 \\
\hline
\end{tabular}

${ }^{\mathrm{a}} \mathrm{OR}$, odds ratio after excluded data from Bornhauser [7].

${ }^{\mathrm{b}}$ Studies that included patients with median age 50 years old and above.

${ }^{\mathrm{c}}$ Studies that included patients with median age below 50 years old.

'Studies that only included patients who had received HCT in the 2000's.

'Studies that included patients who had received HCT in the 1990's.

OR, odds ratio; CI, confidence interval.

who had received HCT in the 2000's (3,261 patients) and studies that included patients who had received HCT in the 1990's (9,722 patients) showed comparable OS patients after RIC-HCT and MAC-HCT (Table 5).

\section{NRM and TRM}

Twenty-two trials $(14,455$ patients) reported NRM/TRM. Eight studies reported significantly lower NRM/TRM rates after RIC-HCT compared to MAC-HCT whereas 14 trials showed no significant difference. Pooled estimates of 22 trials showed significantly lower NRM/TRM after RIC-HCT in the overall $\leq 2$-year and $>2$-year groups (Table 6 and Fig. 3a). Additionally, the significant reduction in NRM after RIC-HCT was observed regardless of the disease type and age of patients. Similarly, the NRM was significantly increased following MAC-HCT among 3,160 patients who had received HCT in 2000's and 11,295 patients who received HCT in 1990's (2000's: $30.9 \%$ vs. $22.5 \%, P<0.02$; 1990's: $25.1 \%$ vs. $21.4 \%, P<0.00001)$. However, there was a trend toward significance in inter-study heterogeneity among the ALL cohort $\left(\mathrm{Chi}^{2}: \mathrm{df}=4, P=0.06 ; I^{2}=55 \%\right)$. We explored the clinical characteristics of each included study and found that the heterogeneity could be explained by one study [30] having significantly older patients in the RICHCT group compared to MAC-HCT. Excluding this study [30] reduced the inter-study heterogeneity $\left(I^{2}=0 \%\right)$ and the pooled analysis of four studies still showed a significantly lower NRM rate after RIC-HCT.

\section{Graft-versus-host disease}

Eighteen trials reported acute $\mathrm{G} v \mathrm{HD}$ (11,972 patients) and 16 trials reported chronic GvHD (6,568 patients). Nine trials showed significantly lower rates of grade II-IV aGvHD after RIC-HCT, whereas nine trials did not show significant difference in $\mathrm{aG} v \mathrm{HD}$ between the two transplant groups. The pooled estimates of 18 trials showed that RIC-HCT had a significantly lower overall occurrence of grade II-IV $\mathrm{aG} v \mathrm{HD}$ compared to MAC-HCT recipients (36\% vs. $43 \%$, OR:0.77 (0.70-0.85). The significant reduction in aGvHD after RIC-HCT was observed regardless of the disease type 
Table 6. Summary of Meta-Analysis of Secondary Outcomes for RIC-HCT Versus MAC-HCT

\begin{tabular}{|c|c|c|c|c|c|c|c|}
\hline $\begin{array}{l}\text { Secondary } \\
\text { outcomes }\end{array}$ & $\begin{array}{l}\text { No. of } \\
\text { studies }\end{array}$ & $\begin{array}{l}\text { No. of patient } \\
\text { RIC (yes/all) }\end{array}$ & $\begin{array}{l}\text { No. of patient } \\
\text { MAC (yes/all) }\end{array}$ & $\begin{array}{l}\text { Heterogeneity } \\
\qquad\left(I^{2}\right)\end{array}$ & $\begin{array}{c}\text { OR } \\
(95 \% C I)\end{array}$ & $\begin{array}{c}\text { OR } \\
\text { (P-value) }\end{array}$ & $\begin{array}{c}\text { OR } \\
\text { (P-value })\end{array}$ \\
\hline \multicolumn{8}{|l|}{$N R M$} \\
\hline Overall & 22 & $925 / 4,275$ & $2,948 / 11,016$ & $35 \%$ & $0.66(0.60,0.73)$ & $<0.00001$ & $<0.00001$ \\
\hline$\leq 2$-year & 15 & $472 / 2,719$ & $1,857 / 7,749$ & $9 \%$ & $0.63(0.56,0.70)$ & $<0.00001$ & $<0.00001$ \\
\hline$>2$-year & 11 & $514 / 1,861$ & $1,218 / 3,732$ & $47 \%$ & $0.73(0.63,0.84)$ & $<0.00001$ & $<0.0001$ \\
\hline AML only & 14 & $499 / 2,862$ & $1,876 / 7,960$ & $29 \%$ & $0.66(0.59,0.74)$ & $<0.00001$ & $<0.00001$ \\
\hline ALL only & 5 & $149 / 519$ & $826 / 2,471$ & $55 \%$ & $0.76(0.61,0.95)$ & 0.02 & 0.02 \\
\hline$\geq 50$ year $^{b}$ & 8 & $501 / 1,874$ & $761 / 2,184$ & $48 \%$ & $0.59(0.52,0.69)$ & $<0.00001$ & $<0.00001$ \\
\hline$<50$ year $^{\mathrm{c}}$ & 6 & $109 / 580$ & $886 / 2,899$ & $29 \%$ & $0.72(0.56,0.91)$ & 0.006 & 0.02 \\
\hline 2000 's d & 7 & $165 / 733$ & $751 / 2,427$ & $49 \%$ & $0.76(0.61,0.94)$ & 0.01 & 0.02 \\
\hline 1990 's & 15 & $713 / 3,327$ & $1,998 / 7,968$ & $28 \%$ & $0.65(0.58,0.72)$ & $<0.00001$ & $<0.00001$ \\
\hline \multicolumn{8}{|l|}{ aGvHD } \\
\hline Overall & 17 & $974 / 2,805$ & $3,804 / 8,965$ & $23 \%$ & $0.79(0.72,0.87)$ & $<0.00001$ & $<0.00001$ \\
\hline $2000{ }^{\prime} s^{d}$ & 7 & $201 / 580$ & $960 / 2,165$ & $36 \%$ & $0.79(0.64,0.98)$ & 0.03 & 0.06 \\
\hline 1990 's & 8 & $744 / 2,164$ & $2,716 / 6,600$ & $51 \%$ & $0.82(0.74,0.91)$ & 0.003 & 0.003 \\
\hline \multicolumn{8}{|l|}{ cGvHD } \\
\hline Overall & 16 & $631 / 1,692$ & $1,973 / 4,876$ & $41 \%$ & $0.83(0.73,0.94)$ & 0.004 & 0.002 \\
\hline $2000 ' s{ }^{d}$ & 5 & $188 / 503$ & $833 / 2,083$ & $45 \%$ & $1.06(0.85,1.33)$ & 0.61 & 0.84 \\
\hline 1990 's ${ }^{\mathrm{e}}$ & 10 & $430 / 1,148$ & $1,115 / 2,748$ & $9 \%$ & $0.76(0.65,0.88)$ & 0.0005 & 0.0005 \\
\hline \multicolumn{8}{|l|}{ Relapse } \\
\hline Overall & 21 & $1,624 / 4,024$ & $3,062 / 10,289$ & $22 \%$ & $1.57(1.45,1.71)$ & $<0.00001$ & $<0.00001$ \\
\hline$\leq 2$-year & 10 & $369 / 1,043$ & $774 / 2,886$ & $0 \%$ & $1.64(1.39,1.93)$ & $<0.00001$ & $<0.00001$ \\
\hline$>2$-year & 12 & $1,208 / 3,009$ & $2,185 / 7,207$ & $43 \%$ & $1.51(1.37,1.66)$ & $<0.00001$ & $<0.00001$ \\
\hline AML only & 14 & $1,412 / 3,444$ & $2,419 / 7,733$ & $30 \%$ & $1.51(1.38,1.66)$ & $<0.00001$ & $<0.00001$ \\
\hline ALL only & 5 & $215 / 725$ & $662 / 2,840$ & $0 \%$ & $1.77(1.45,2.17)$ & $<0.00001$ & $<0.00001$ \\
\hline CR1 & 6 & $200 / 534$ & $383 / 1,665$ & $28 \%$ & $2.08(1.66,2.62)$ & $<0.00001$ & $<0.00001$ \\
\hline$\geq 50$ year $^{\mathrm{b}}$ & 8 & $721 / 1,875$ & $554 / 2,134$ & $26 \%$ & $1.70(1.47,1.96)$ & $<0.00001$ & $<0.00001$ \\
\hline$<50$ year $^{\mathrm{c}}$ & 6 & $252 / 580$ & $891 / 2,899$ & $0 \%$ & $1.37(1.12,1.68)$ & 0.002 & 0.002 \\
\hline 2000 's & 8 & $300 / 772$ & $700 / 2,489$ & $10 \%$ & $1.55(1.28,1.89)$ & $<0.00001$ & $<0.00001$ \\
\hline 1990 's & 13 & $1,248 / 3,074$ & $2,215 / 7,235$ & $26 \%$ & $1.55(1.41,1.70)$ & $<0.00001$ & $<0.00001$ \\
\hline
\end{tabular}

${ }^{\mathrm{a} O R}$, odds ratio after excluded data from Bornhauser [7].

${ }^{\mathrm{b}}$ Studies that included patients with median age 50 years old and above.

'Studies that included patients with median age below 50 years old.

${ }^{\mathrm{d}}$ Studies that only included patients who had received HCT in the 2000's.

'Studies that included patients who had received HCT in the 1990's.

NRM, nonrelapsed mortality; aGvHD, acute graft-versus-host disease; cGvHD, chronic graft-versus-host disease.

and timing of the transplant. The aGvHD rate was significantly increased following MAC-HCT among 2,745 patients who had received HCT at/after year 2000 and 8,824 patients who received HCT in 1990's. However, there was a statistically significant inter-study heterogeneity $\left(\mathrm{Chi}^{2}\right.$ : $\mathrm{df}=18$, $\left.P<0.005 ; I^{2}=53 \%\right)$. We explored the clinical characteristics of each included study, and found that the heterogeneity could be explained by one study [31] having significantly older patients in the RIC-HCT group compared to MACHCT. Excluding this study [31] reduced the inter-study heterogeneity $\left(I^{2}=23 \%\right)$ and the pooled estimates of 17 studies still showed lower grade II-IV aGvHD after RICHCT (Table 6 and Fig. 3b).

Almost all (14 of 16) of the included trials reported comparable rates of $\mathrm{cG} v \mathrm{HD}$ between RIC-HCT and MACHCT. Shimoni et al. [2] showed a significantly higher $\mathrm{cG} v \mathrm{HD}$, whereas Parker et al. [32] showed lower cGvHD rates among RIC-HCT recipients. Pooled analysis of all 16 trials showed lower $\mathrm{cG} v \mathrm{HD}$ rate after RIC-HCT compared to MAC-HCT. The sub-analysis according to timing of HCT involving 2,586 patients (five trials) who had received HCT at/after year 2000 and 3,896 patients (eight trials) who had received HCT in 1990's showed that cGvHD rate was significantly higher following MAC-HCT compared to RICHCT among patients who received HCT in 1990's. There was no substantial inter-study heterogeneity for the $\mathrm{cG} v \mathrm{HD}$ data.

\section{Relapse}

Twenty-one trials (14,313 patients) reported RR. Nine trials showed higher RR after RIC-HCT compared to MACHCT whereas 12 trials showed no significant difference in RR between the two regimens. Pooled estimates of 21 trials showed that the RR was significantly higher after RIC-HCT than MAC-HCT. RIC-HCT recipients had a significantly lower $\leq 2$-year and $>2$-year RR (Table 6 and Fig. 3c). The RR of RIC-HCT was higher than MAC-HCT regardless of disease type, age of patients, and timing of HCT (HCT performed in 2000's versus 1990's). Pooled estimates of 6 clinical trials showed a higher RR after RIC-HCT than MAC-HCT even in patients transplanted in CR1. The RR was significantly increased following RIC-HCT among 3,261 patients who had received HCT in 2000's and 10,309 patients who received HCT in 1990's. 
a



\section{b}

RIC MAC

Odds Ratio

Odds Ratio

Stucty or Subgroup Events Total Events Total Weight M-H, Fixed, 95\% Cl

$\mathrm{M}-\mathrm{H}$, Fixed, $95 \% \mathrm{Cl}$

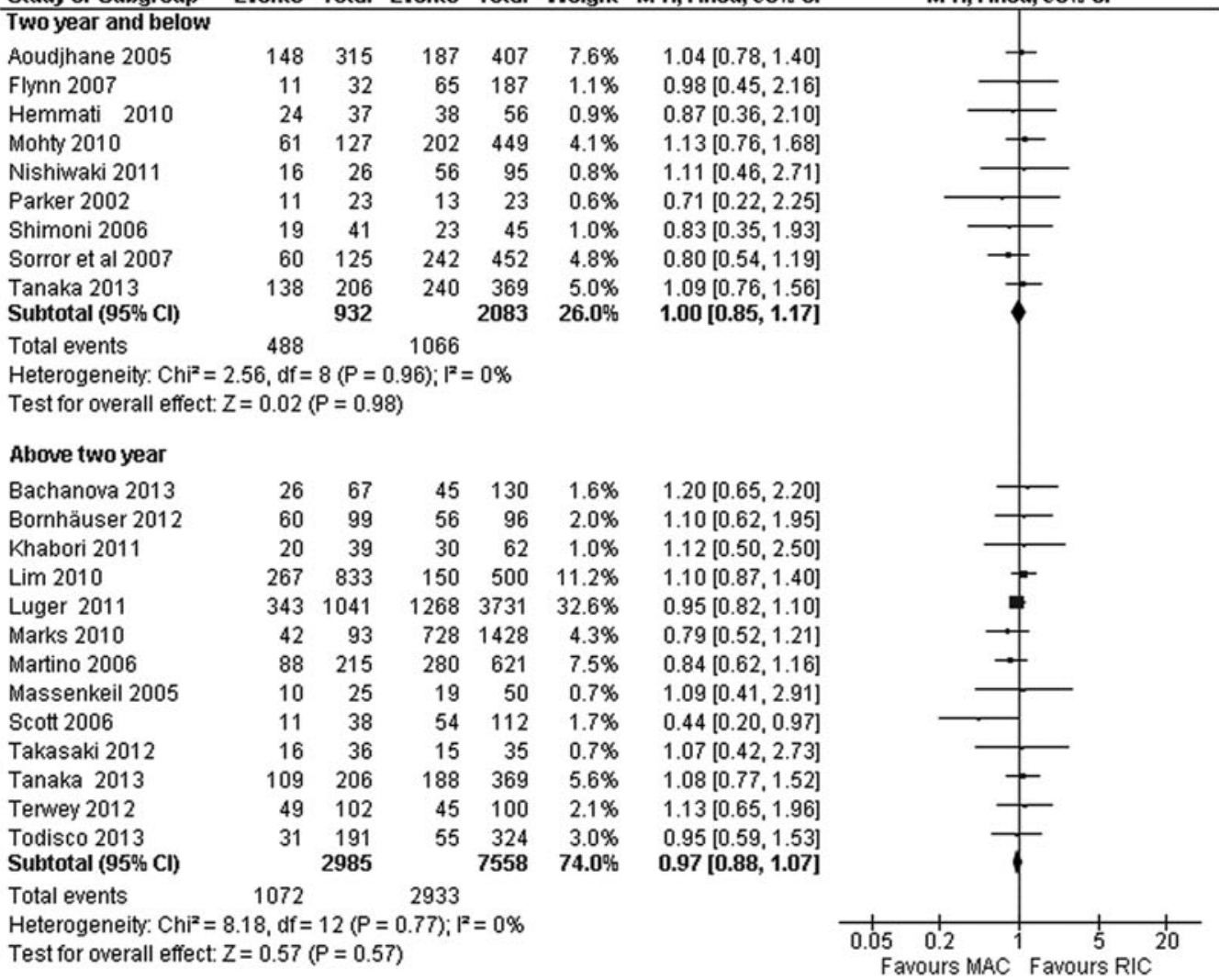

FIG. 2. (a) Progression-free survival: $\leq 2$-year and $>2$-year in RIC-HCT versus MAC-HCT. (b) Overall survival: $\leq 2$ year and >2-year in RIC-HCT versus MAC-HCT. HCT, hematopoietic stem cell transplantation; MAC, myeloablative conditioning; RIC, reduced-intensity conditioning. 
RIC $\quad$ MAC Stucty or Subgroup Events

\begin{tabular}{|c|c|c|c|c|c|}
\hline Aoudjhane 2005 & 57 & 315 & 130 & 407 & $7.6 \%$ \\
\hline Bachanova 2013 & 9 & 67 & 47 & 130 & $2.3 \%$ \\
\hline Bornhäuser 2012 & 8 & 99 & 16 & 96 & $1.2 \%$ \\
\hline Flynn 2007 & 11 & 32 & 62 & 187 & $1.0 \%$ \\
\hline Hemmati 2010 & 6 & 37 & 10 & 56 & $0.5 \%$ \\
\hline LUGER 2011 & 131 & 1005 & 659 & 3659 & $20.1 \%$ \\
\hline Martino 2006 & 32 & 215 & 124 & 621 & $4.4 \%$ \\
\hline Mohty 2010 & 27 & 127 & 130 & 449 & $3.7 \%$ \\
\hline Nishiwaki 2011 & 9 & 26 & 38 & 95 & $0.9 \%$ \\
\hline Parker 2002 & 6 & 23 & 14 & 29 & $0.7 \%$ \\
\hline Ringdén 2009 ( $\leq 50 y r)$ & 37 & 149 & 321 & 972 & $5.2 \%$ \\
\hline Ringdén 2009 ( $~(50 y r)$ & 63 & 252 & 71 & 182 & $5.0 \%$ \\
\hline Shimoni 2006 & 3 & 41 & 10 & 45 & $0.7 \%$ \\
\hline Sorror et al 2007 & 20 & 125 & 114 & 452 & $3.4 \%$ \\
\hline $\begin{array}{l}\text { Tanaka } 2013 \\
\text { Subtotal }(95 \% \mathrm{Cl})\end{array}$ & 53 & $\begin{array}{r}206 \\
2719\end{array}$ & 111 & $\begin{array}{r}369 \\
7749\end{array}$ & $\begin{array}{r}4.8 \% \\
61.6 \%\end{array}$ \\
\hline \multicolumn{6}{|c|}{$\begin{array}{l}\text { Heterogeneity: } \mathrm{Ch}^{2}=15.40, \mathrm{df}=14(\mathrm{P}=0.35) ; \mathrm{I}^{2}=9 \% \\
\text { Test for overall effect: } Z=7.83(P<0.00001)\end{array}$} \\
\hline \multicolumn{6}{|l|}{ NRM+TRM > two year } \\
\hline Bornhäuser 2012 & 13 & 99 & 17 & 96 & $1.2 \%$ \\
\hline Graef 2007 & 12 & 23 & 33 & 97 & $0.5 \%$ \\
\hline Lim 2010 & 267 & 833 & 220 & 500 & $15.2 \%$ \\
\hline Marks 2010 & 30 & 93 & 471 & 1428 & $3.2 \%$ \\
\hline Martino 2006 & 47 & 215 & 199 & 621 & $6.5 \%$ \\
\hline Massenkeil 2005 & 1 & 25 & 12 & 50 & $0.6 \%$ \\
\hline Scott 2006 & 16 & 38 & 38 & 112 & $0.9 \%$ \\
\hline Takasaki 2012 & 9 & 36 & 14 & 35 & $0.9 \%$ \\
\hline Tanaka 2013 & 74 & 206 & 140 & 369 & $5.2 \%$ \\
\hline Terwey 2012 & 18 & 102 & 22 & 100 & $1.5 \%$ \\
\hline $\begin{array}{l}\text { Todisco } 2013 \\
\text { Subtotal }(95 \% \mathrm{Cl})\end{array}$ & 27 & $\begin{array}{r}191 \\
1861\end{array}$ & 52 & $\begin{array}{r}324 \\
3732\end{array}$ & $\begin{array}{r}2.7 \% \\
\mathbf{3 8 . 4} \%\end{array}$ \\
\hline Total events & 514 & & 1218 & & \\
\hline
\end{tabular}

Fixed

, $95 \% \mathrm{Cl}$

$0.47[0.33,0.67]$

$0.27[0.12,0.60]$

$0.44[0.18,1.08]$

$1.06[0.48,2.33]$

$0.89[0.29,2.70]$

$0.68[0.56,0.84]$

$0.70[0.46,1.07]$

$0.66[0.41,1.06]$

$0.79[0.32,1.97]$

$0.38[0.12,1.23]$

$0.67[0.45,0.99]$

$0.52[0.35,0.79]$

$0.28[0.07,1.09]$

$0.56[0.33,0.95]$

$0.81[0.55,1.18]$

$0.63[0.56,0.70]$



b

RIC

MAC

$0.70[0.32,1.54]$

$2.12[0.84,5.31]$

$0.60[0.48,0.75]$

$0.97[0.62,1.52]$

$0.59[0.41,0.85]$

$0.13[0.02,1.08]$

$1.42[0.67,3.01]$

$0.50[0.18,1.38]$

$0.92[0.64,1.31]$

$0.76[0.38,1.52]$

$0.86[0.52,1.43]$

(0.63, 0.84$]$

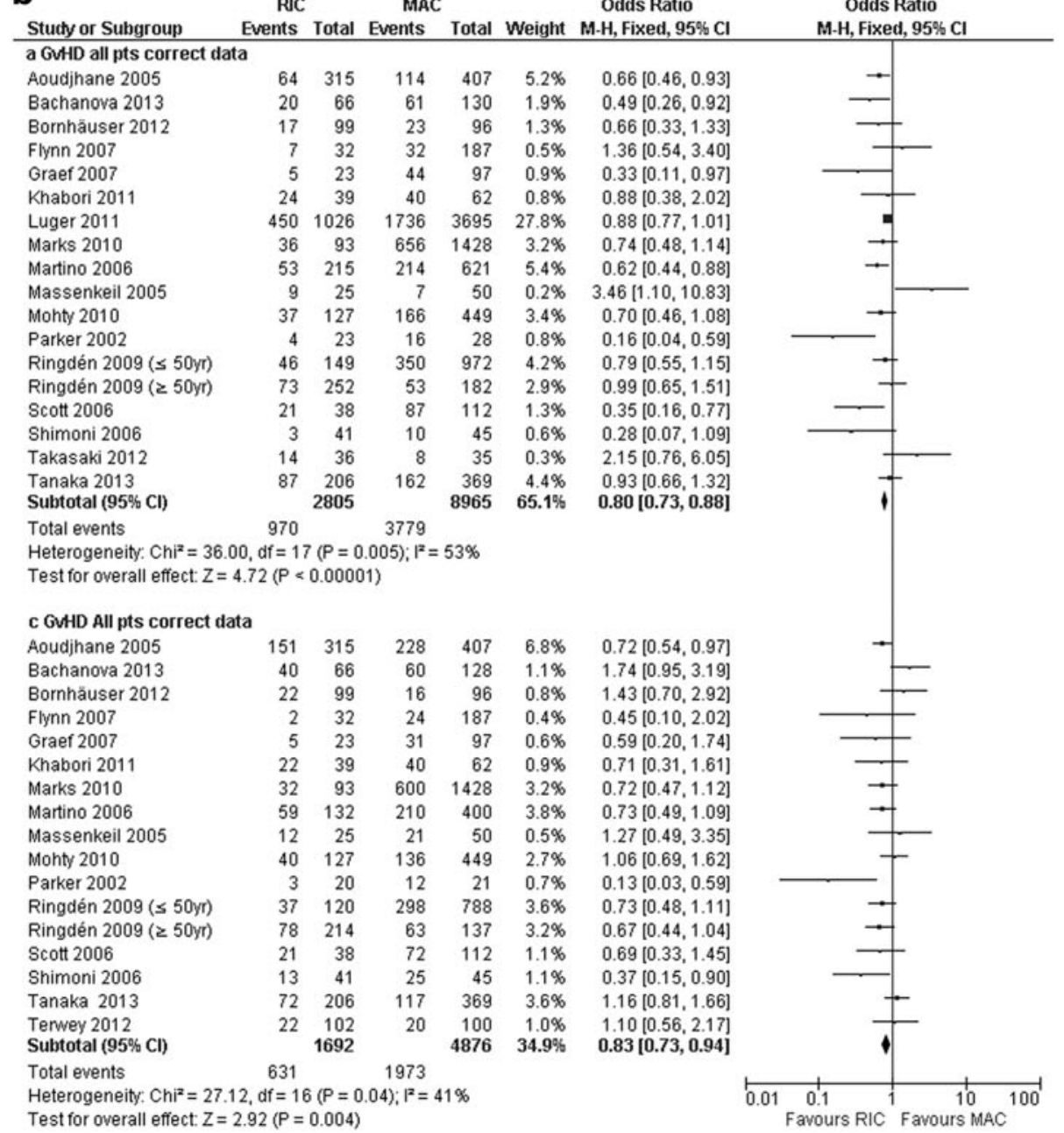

FIG. 3. (a) Nonrelapsed mortality: $\leq 2$-year and $>2$-year in RIC-HCT versus MAC-HCT. (b) $>$ Acute $\mathrm{G} v \mathrm{HD}$ and chronic $\mathrm{G} v \mathrm{HD}$ in RIC-HCT versus MACHCT. (c) Relapse rate: $\leq 2$-year and $>2$-year in RIC-HCT versus MAC-HCT. GvHD, acute graftversus-host disease. 


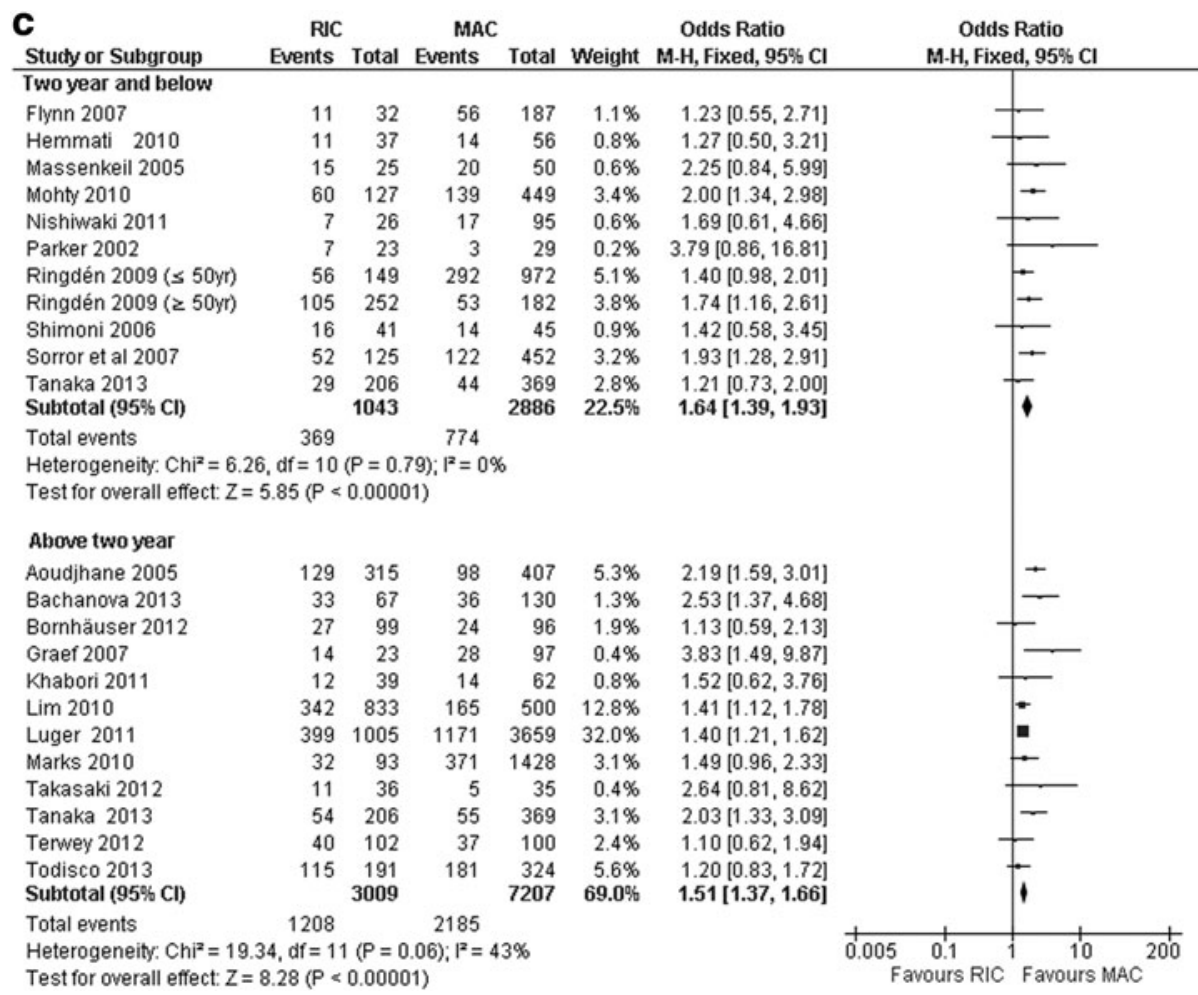

There was no substantial inter-study heterogeneity for this outcome in all analyses ( $I^{2}$ ranged from $0 \%$ to $\left.43 \%\right)$.

\section{Assessment of publication bias}

There was no evidence of obvious asymmetry in all the funnel plots, except for the outcome of $>2$-year PFS (Fig. 4). Although the shape of this funnel plot does not amount to gross asymmetry, it suggests that smaller studies with outcomes favoring RIC appeared to be lacking.

\section{Discussion}

To determine the relationship between dose intensity of conditioning regimen and survival outcomes after allografting in acute leukemias and high-risk MDS patients, we

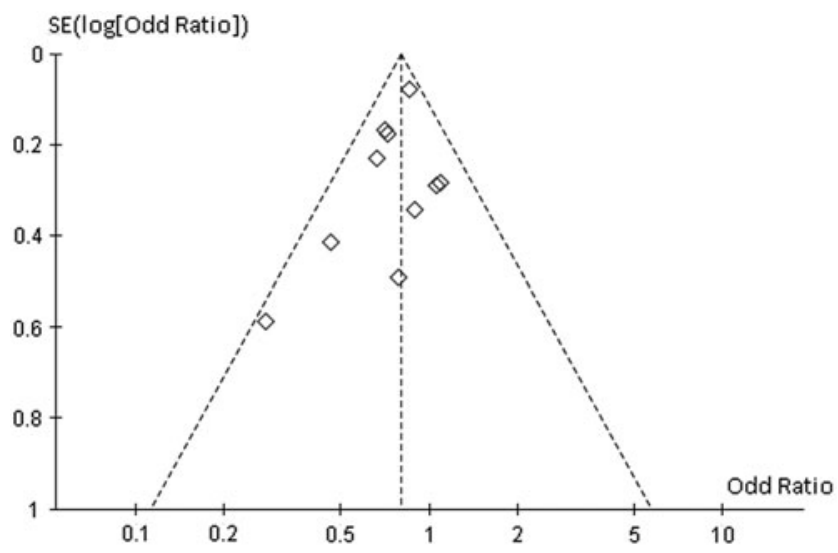

FIG. 4. Funnel plot for disease-free survival (above 2 years) comparing RIC-HCT versus MAC-HCT. presented the first meta-analysis of all clinical trials conducted from 1990 until 2013 that compare survival rates in patients transplanted with RIC versus MAC regimens. The systematic literature search identified 23 relevant comparative trials, none of which showed OS benefit of MAC over RIC regimens. In fact, two clinical trials (one prospective) [22] and one retrospective [23] that compared survival rates between the conventional MAC and the novel RTC regimens that was excluded from this present meta-analysis showed that MAC regimen was associated with inferior OS and EFS.

The present meta-analysis supported previous observation that RIC resulted in comparable OS rates with MAC regimens among overall cohort of patients for up to 6 years after transplant even though the RIC-HCT recipients was older and had more advanced disease than MAC-HCT recipients. This favorable OS rates could be attributed to the remarkably reduced NRM in the overall cohort of patients receiving RIC-HCT. Of note, there was no significant change in OR values for all transplant outcomes derived after a separate analysis was performed for retrospective studies versus RCT. Similarly, except for $\mathrm{cG} v \mathrm{HD}$ data, there were no significant difference in OR values for survival, NRM, relapse, and $\mathrm{aG} v \mathrm{HD}$ rates between the two regimens even after a separate analysis was performed for trials that included patients who received HCT in 1990's versus those who received HCT at/after year 2000.

\section{OS and PFS according to disease type}

The present meta-analysis showed that the 1-6 years PFS and OS rates after RIC-HCT in overall cohort of AML patients were $30 \%-60 \%$, which is consistent with single-arm retrospective landmark studies on RIC in AML patients 
reporting a 2-3 year LFS ranging from $27 \%$ to $60 \%$ and OS rates of $30 \%$ to $60 \%[5,10,33-36]$. We did not observe significant change in OR values for survival rates and other transplant outcomes even if separate analyses were performed for retrospective studies versus RCT. We showed no OS advantage of MAC-HCT over RIC-HCT in AML patients transplanted in CR1 and non-CR1.

The published experience of RIC-HCT for ALL is not as extensive or mature as it is for myeloid malignancies and there are no prospective randomized trials comparing RICHCT and MAC-HCT. All the individual trials, including multicenter registry surveys (EBMT, CIBMTR, JSHCT database) [11,12,29,30,37], showed comparable PFS and OS rates in ALL patients after RIC-HCT and MAC-HCT and that RIC regimen was not an independent risk factor for survival outcomes in multivariate analyses [11,12,29,37]. In contrast, the pooled analysis of these studies showed that PFS in ALL patients was significantly lower after RIC-HCT than MAC-HCT $(35.5 \%$ vs. $41.3 \%, P<0.01)$. This lower PFS was probably offset by the remarkably lower NRM in RIC-HCT resulting in comparable OS with MAC-HCT. Thus, our meta-analysis demonstrated the lack of OS benefit of MAC over RIC regimens in the overall cohort of ALL patients suggesting that RIC-HCT may be a potential therapeutic option in patients with high risk of TRM associated with the MAC regimens.

This meta-analysis showed that the $>2$-year PFS rate was higher after MAC-HCT, in particular, in patients aged below 50 years suggesting that in younger patients with acute leukemia/high-risk MDS, MAC-HCT may still be the preferred therapeutic option.

\section{OS and PFS according to disease status at transplantation}

The impact of dose intensity of the conditioning regimen on transplant outcomes in acute leukemia patients receiving allografting in CR1 remains ill defined. There are no randomized controlled trial comparing RIC-HCT and MACHCT in ALL patients transplanted in CR1, whereas there is only one randomized trial comparing the two regimens for AML-CR1 patients [7]. This prospective randomized trial in AML-CR1 patients showed that the 3-year PFS and OS rates did not differ significantly between the two transplant regimens [7]. Similarly, nonrandomized studies demonstrated that survival rates among RIC and MAC recipients tended to be similar when the study was limited to AML patients transplanted in CR1 [2,8,9,26,38]. The present meta-analysis extends available data showing that RIC-HCT and MACHCT produce equivalent OS in the AML + MDS patients transplanted in CR1. The significantly higher late (up to 6 years) PFS rates in AML + MDS patients transplanted in CR1 observed after MAC-HCT is offset by a significantly lower NRM resulting in comparable OS rates with RIC-HCT.

Similarly, there was no survival benefit of MAC-HCT over RIC-HCT in ALL patients transplanted in CR1. Overall, these findings showed that RIC-HCT is a valid transplant option for AML and ALL patients in CR1.

Of note, among the overall cohort of patients transplanted in non-CR1, RIC-HCT provided a better OS than MACHCT. This is probably attributed to a significantly lower NRM and similar PFS rates in RIC-HCT recipients com- pared to MAC-HCT recipients. The similar PFS rates may suggest that the $\mathrm{G} v \mathrm{~L}$ is still operational even in patients with an advance phase of the disease.

On the other hand, in our analysis, among the entire cohort of patients that received the same conditioning regimen, OS and PFS were significantly better if the patients received transplant in CR1 compared to those transplanted in nonCR1, indicating that disease status at the time of transplantation remains an important predictor for survival after HCT in acute leukemia/MDS patients. Our findings are in agreement with earlier studies [2,39], showing that RIC regimen is associated with an improved survival in AML patients if performed in CR (in particular CR1) than active disease. Thus, AML patients with active disease at the time of transplantation should not be considered for RIC-HCT unless a morphological remission can be achieved with salvage chemotherapy [40].

\section{OS and PFS according to the timing of transplantation}

We have performed sub-group analyses according to the timing of HCT and obtained the pooled estimates (OR) for survival rates for patients who had received HCT at/after year 2000 (2000s HCT) and before year 2000 (1990s HCT). We decided to take year 2000 as the cut-off point for our subgroup analysis, as major transplant innovation and new technologies that allegedly improve the survival outcomes of HCT was introduced in year 2000 and thereafter. Moreover, published meta-analyses on HCT comparing Cord Blood and Unrelated donor transplant and RIC versus MACHCT in various hematological malignancies have included HCT performed in year 2000 and beyond $[15,16]$.

The results showed that there was no significant difference in the survival outcomes, and other transplant outcomes, except for $\mathrm{cG} v \mathrm{HD}$ among patients who had received HCT at/after year 2000 (2000s HCT) and before year 2000 (1990s HCT).

\section{Acute and chronic GvHD}

$\mathrm{G} v \mathrm{HD}$ continues to be one of the major limitations to the success of allogeneic HSCT. The cytokine storm that arises following MAC regimen plays a prominent role in the initiation and maintenance of $\mathrm{G} v \mathrm{HD}$ [13]. RIC regimen causes less tissue damage, releases lower levels of proinflammatory cytokines, and induces T-cell mixed chimerism, which might translate into a reduced incidence and severity of $\mathrm{G} v \mathrm{HD}$ [41-43].

In support of the above observations, the present metaanalysis showed that RIC-HCT recipients had significantly low-grade II-IV aGvHD and $\mathrm{cG} v \mathrm{HD}$ even though significantly more of the RIC-HCT patients were older and received PBSC.

Our findings are in keeping with the findings reported by a prospective clinical trial that evaluates the influence of conditioning regimen intensity on the incidence and severity of $\mathrm{G} v \mathrm{HD}$ [44]. The study that included 137 patients undergoing HLA identical-sibling transplantation $(\mathrm{MAC}=74$; $\mathrm{RIC}=63$ ) who had received a common regimen of $\mathrm{G} v \mathrm{HD}$ prophylaxis showed that the rate of grade II-IV aGvHD and $\mathrm{cG} v \mathrm{HD}$ were lower in patients receiving RIC-HCT than 
MAC-HCT ( $36 \%$ vs. $12 \%, 14 \%$ vs. $40 \%$, respectively), even though RIC recipients were older, had more advanced disease, had more extensive prior therapies, and had higher comorbidities at transplantation [44].

Overall, these data support the theoretical advantage of using a less toxic and intensive conditioning regimen in reducing the incidence of $\mathrm{aG} v \mathrm{HD}$ and because $\mathrm{aG} v \mathrm{HD}$ is a risk factor for developing $\mathrm{cGvHD}$, its occurrence may indirectly be reduced as well.

\section{Nonrelapse mortality/treatment-related mortality}

Despite the fact that older patients and lower number of patients in CR had received RIC-HCT, the present metaanalysis showed that compared to MAC-HCT, RIC-HCT was associated with significantly reduced NRM up to 6 years posttransplant period across the entire cohort of patients, highlighting the predominant effect of the conditioning intensity on the development of NRM.

This finding is in agreement with a prior meta-analysis that involved over 5,000 patients with a variety of hematological malignancies showing a significantly lower incidence of TRM (OR: 0.61 (95\% CI, 0.53-0.69) after RICHCT [15].

The reduction in infection coupled with the lower incidence of $\mathrm{G} v \mathrm{HD}$ could possibly contribute to the reduced NRM in our RIC-HCT recipients.

\section{Relapse}

Previous data has demonstrated that the risk of relapse is associated with the intensity of the conditioning regimen. With more intensified chemoradiotherapy, relapse is decreased [45]. Therefore, an increase in RR after RIC versus MAC transplants may be expected, as evident in the present meta-analysis showing that RIC-HCT led to nearly 1.3-fold increase in RR across the entire cohort of patients. The RR associated with RIC-HCT regimen was higher regardless of disease type (AML or ALL), disease status (CR1 or nonCR1), age of patients ( $<$ or $\geq 50$ years), and timing of HCT (HCT performed in 2000's versus those performed in 1990's).

Based on the concept that $\mathrm{G} v \mathrm{HD}$ can facilitate a $\mathrm{G} v \mathrm{~L}$ effect, the significant reduction in $\mathrm{G} v \mathrm{HD}$ rates in particular $\mathrm{cG} v \mathrm{HD}$ and the use of ATG as $\mathrm{G} v \mathrm{HD}$ prophylaxis in RIC regimen could explain the increased RR and subsequently reduced PFS at longer follow-up among RIC-HCT recipients. This is particularly significant for patients who are not in remission at the time of transplantation because the $\mathrm{G} v \mathrm{~L}$ effect takes time to develop and the underlying malignancy may outpace the $\mathrm{G} v \mathrm{~L}$ effect $[3,5,6,46-49]$. Thus the search for improved conditioning regimen with enhanced antileukemia properties without increased treatment-related toxicity would be of significant benefit.

The novel RTC regimen incorporating myeloablative doses of alkylating agents was developed to reduce the RR associated with RIC regimens [18]. The safety and efficacy of RTC regimen in patients with advanced AML+MDS patients was first demonstrated by a single-arm study that included a large number of AML + MDS patients, mostly beyond CR1 that showed impressive survival rates with remarkably low transplant toxicity (1-year NRM, OS, EFS were $3 \%, 65 \%, 52 \%$, respectively) [1]. This encouraging survival outcomes associated with RTC regimen was further supported by a prospective nonrandomized study [22] involving 215 AML + MDS patients (50\%-60\% with active disease) showing that compared to MAC-HCT, RTC-HCT led to superior survival rates and similar RR, suggesting that RTC regimens may be a more attractive option than RIC regimen in patients not eligible for MAC-HCT and not in CR before allografting.

\section{Limitation}

Important limitations to the comparison of conditioning regimens are the lack of (1) homogenous criteria to select patients for the two different conditioning regimens, (2) uniformity to the type of conditioning regimens and $\mathrm{G} v \mathrm{HD}$ prophylaxis, (3) uniformity of the source of donor stem cells [19]. It is not possible to determine the transplant outcomes of a particular RIC regimen as some studies used various combination chemoradiotherapy and most of the included studies did not report outcomes for a particular regimen.

Importantly, most studies that were included in our metaanalysis allocated patients to RIC-HCT versus MAC-HCT based on age, presence of comorbidities, and performance status. Therefore, these studies suffer from significant selection bias. Furthermore, the median age of the patients in the RIC group was 53 years, which means that the results cannot be extrapolated to older patients with acute leukemia and high-risk MDS in whom RIC-HCT might be an attractive option.

Most studies did not report separately the survival outcomes according to patient's age, cytogenetic risk, type of donor, and source of stem cell, thus we were not able to determine the influence of established prognostic factors on transplant outcomes associated with the two conditioning regimens. As there was inadequate survival and relapse data reported for patients with advanced and active disease, the impact of dose intensity in this setting cannot be evaluated.

Only one study was a RCT, whereas the rest were retrospective studies with greater inherent risk of bias. The lack of a control group, the use of historical controls for MAC-HCT group, the limited follow-up period, and the absence of uniform and objective clinical assessment, which are the inherent pitfalls of retrospective studies, should prompt us to interpret the results of the present meta-analysis with caution. Therefore, in our meta-analysis, to reduce the effect of heterogeneity in study design, OR values for all transplant outcomes were also calculated from a separate pooled analysis of data obtained from all the retrospective studies versus data from RCT (shown in Tables 5 and 6).

\section{Conclusion}

The present meta-analysis showed that RIC regimens resulted in comparable OS rates with MAC regimens in acute leukemia/MDS patients for up to 6 years after transplant even though the RIC-HCT recipients were older and had more active disease than MAC-HCT recipients suggesting that dose intensity of conditioning regimen may not have independent impact on OS. The higher PFS observed beyond 2 years of MACT-HCT was offset by a consistently higher rate of NRM resulting in equivalent OS with RIC- 
HCT suggesting that RIC-HCT provides a feasible therapeutic option in acute leukemia and high-risk MDS patients with significant risk of treatment-related toxicities.

Among patients that received the same conditioning regimen, survival rates were superior if the patients were transplanted in CR1, suggesting that disease status at the time of transplant remains an important prognostic factor of survival after allografting in acute leukemia and MDS. The meta-analysis showed that a less intensive conditioning regimen would be associated with less aGvHD, and consequently less $\mathrm{cG} \nu \mathrm{HD}$ and NRM, but more relapse. New strategies aimed at reducing relapse without increasing transplant-related toxicities, including improvement in conditioning regimen, induction of potent $\mathrm{G} v \mathrm{~L}$ effects, and postgrafting immunomodulation are required.

Large-scale, well-designed, randomized, controlled trials are required to obtain an unbiased estimate of the effect of conditioning dose intensity on survival outcomes before RIC or RTC regimens can be recommended as the standard of care in patients with acute leukemia and high-risk MDS requiring allogeneic $\mathrm{HCT}$, and to identify a transplant regimen that would best suit an individual patient. In the meantime, RIC-HCT is a valid alternative treatment for AML, MDS, and ALL patients ineligible for MAC-HCT and CR status is preferred before allografting.

\section{Acknowledgments}

The authors would like to thank Umi Norafitah Hawa binti Mohd Dan, Siti Noor Fatimah binti Mohd Zain, and Siti Suhaina binti Mat Tarihan for their technical assistance in the preparation of the article and the dean of faculty of medicine, UKM Medical Center for his continuous support.

\section{Author Disclosure Statement}

The authors declare no competing financial interests.

\section{References}

1. de Lima M, A Anagnostopoulos, M Munsell, M Shahjahan, N Ueno, C Ippoliti, BS Andersson, J Gajewski, D Couriel, et al. (2004). Nonablative versus reduced-intensity conditioning regimens in the treatment of acute myeloid leukemia and high-risk myelodysplastic syndrome: dose is relevant for long-term disease control after allogeneic hematopoietic stem cell transplantation. Blood 104:865-872.

2. Shimoni A, I Hardan, N Shem-Tov, M Yeshurun, R Yerushalmi, A Avigdor, I Ben-Bassat and A Nagler. (2006). Allogeneic hematopoietic stem-cell transplantation in AML and MDS using myeloablative versus reduced-intensity conditioning: the role of dose intensity. Leukemia 20:322328.

3. Fadilah SA and MP Aqilah. (2012). Promising role of reduced-toxicity hematopoietic stem cell transplantation (PART-I). Stem Cell Rev 8:1254-1264.

4. Champlin R, I Khouri, A Shimoni, J Gajewski, S Kornblau, J Molldrem, N Ueno, S Giralt and P Anderlini. (2000). Harnessing graft-versus-malignancy: non-myeloablative preparative regimens for allogeneic haematopoietic transplantation, an evolving strategy for adoptive immunotherapy. Br J Haematol 111:18-29.
5. Hemmati PG, TH Terwey, G Massenkeil, P le Coutre, LG Vuong, S Neuburger, B Dorken and R Arnold. (2010). Reduced intensity conditioning prior to allogeneic stem cell transplantation in first complete remission is effective in patients with acute myeloid leukemia and an intermediaterisk karyotype. Int J Hematol 91:436-445.

6. Laport GG, BM Sandmaier, BE Storer, BL Scott, MJ Stuart, T Lange, MB Maris, ED Agura, TR Chauncey, et al. (2008). Reduced-intensity conditioning followed by allogeneic hematopoietic cell transplantation for adult patients with myelodysplastic syndrome and myeloproliferative disorders. Biol Blood Marrow Transplant 14:246-255.

7. Bornhauser M, J Kienast, $\mathrm{R}$ Trenschel, A Burchert, U Hegenbart, M Stadler, H Baurmann, K Schafer-Eckart, E Holler, et al. (2012). Reduced-intensity conditioning versus standard conditioning before allogeneic haemopoietic cell transplantation in patients with acute myeloid leukaemia in first complete remission: a prospective, open-label randomised phase 3 trial. Lancet Oncol 13:1035-1044.

8. Aoudjhane M, M Labopin, NC Gorin, A Shimoni, T Ruutu, HJ Kolb, F Frassoni, JM Boiron, JL Yin, et al. (2005). Comparative outcome of reduced intensity and myeloablative conditioning regimen in HLA identical sibling allogeneic haematopoietic stem cell transplantation for patients older than 50 years of age with acute myeloblastic leukaemia: a retrospective survey from the Acute Leukemia Working Party (ALWP) of the European group for Blood and Marrow Transplantation (EBMT). Leukemia 19:2304-2312.

9. Martino R, S Iacobelli, R Brand, T Jansen, A van Biezen, J Finke, A Bacigalupo, D Beelen, J Reiffers, et al. (2006). Retrospective comparison of reduced-intensity conditioning and conventional high-dose conditioning for allogeneic hematopoietic stem cell transplantation using HLA-identical sibling donors in myelodysplastic syndromes. Blood 108:836-846.

10. Luger SM, O Ringden, MJ Zhang, WS Perez, MR Bishop, M Bornhauser, CN Bredeson, MS Cairo, EA Copelan, et al. (2012). Similar outcomes using myeloablative vs reducedintensity allogeneic transplant preparative regimens for AML or MDS. Bone Marrow Transplant 47:203-211.

11. Marks DI, T Wang, WS Perez, JH Antin, E Copelan, RP Gale, B George, V Gupta, J Halter, et al. (2010). The outcome of full-intensity and reduced-intensity conditioning matched sibling or unrelated donor transplantation in adults with Philadelphia chromosome-negative acute lymphoblastic leukemia in first and second complete remission. Blood 116:366-374.

12. Mohty M, M Labopin, L Volin, A Gratwohl, G Socie, J Esteve, R Tabrizi, A Nagler and V Rocha. (2010). Reducedintensity versus conventional myeloablative conditioning allogeneic stem cell transplantation for patients with acute lymphoblastic leukemia: a retrospective study from the European Group for Blood and Marrow Transplantation. Blood 116:4439-4443.

13. Horwitz ME. (2011). Reduced intensity versus myeloablative allogeneic stem cell transplantation for the treatment of acute myeloid leukemia, myelodysplastic syndrome and acute lymphoid leukemia. Curr Opin Oncol 23:197-202.

14. Labopin M and S Iacobelli. (2003). STATISTICAL GUIDELINES FOR EBMT. https://portal.ebmt.org/sites/ clint2/clint/Documents/StatGuidelines_oct2003.pdf Last accessed November 19, 2013.

15. Shi-Xia X, X Hai-Qin, T Xian-Hua, F Bo and T XiangFeng. (2011). Comparison of reduced intensity and myeloablative conditioning regimens for stem cell transplantation 
in patients with malignancies: a meta-analysis. Clin Transplant 25:E187-E198.

16. Zhang H, J Chen and W Que. (2012). A meta-analysis of unrelated donor umbilical cord blood transplantation versus unrelated donor bone marrow transplantation in acute leukemia patients. Biol Blood Marrow Transplant 18:11641173.

17. Koreth J, R Schlenk, KJ Kopecky, S Honda, J Sierra, BJ Djulbegovic, M Wadleigh, DJ DeAngelo, RM Stone, et al. (2009). Allogeneic stem cell transplantation for acute myeloid leukemia in first complete remission: systematic review and meta-analysis of prospective clinical trials. JAMA 301:2349-2361.

18. Shimoni A and A Nagler. (2011). Optimizing the conditioning regimen for allogeneic stem-cell transplantation in acute myeloid leukemia; dose intensity is still in need. Best Pract Res Clin Haematol 24:369-379.

19. Hamadani M, M Mohty and MA Kharfan-Dabaja. (2011). Reduced-intensity conditioning allogeneic hematopoietic cell transplantation in adults with acute myeloid leukemia. Cancer Control 18:237-245.

20. Pidala J, B Djulbegovic, C Anasetti, M Kharfan-Dabaja and A Kumar. (2011). Allogeneic hematopoietic cell transplantation for adult acute lymphoblastic leukemia (ALL) in first complete remission. Cochrane Database Syst Rev 10: CD008818.

21. Liu H, W Stock and MR Bishop. (2013). Expanded indications for allogeneic stem cell transplantation in patients with myeloid malignancies. Curr Opin Hematol 20:115122.

22. Andersson BS, M de Lima, PF Thall, X Wang, D Couriel, M Korbling, S Roberson, S Giralt, B Pierre, et al. (2008). Once daily i.v. busulfan and fludarabine (i.v. Bu-Flu) compares favorably with i.v. busulfan and cyclophosphamide (i.v. BuCy2) as pretransplant conditioning therapy in AML/MDS. Biol Blood Marrow Transplant 14:672-684.

23. Goker H, E Ozdemir, B Uz, Y Buyukasik, M Turgut, S Serefhanoglu, S Aksu, N Sayinalp, IC Haznedaroglu, et al. (2013). Comparative outcome of reduced intensity and myeloablative conditioning regimen in HLA identical sibling allogeneic hematopoietic stem cell transplantation for acute leukemia patients: A single center experience. Transfus Apher Sci 49:590-599.

24. Raida L, P Tucek, E Faber, J Vondrakova, Z Rusinakova, I Skoumalova, J Hubacek, M Jarosova, B Katrincsakova, et al. (2011). Comparison of new flu-bu12-tg conditioning with the standard bu-cy myeloablative regimen in patients undergoing allogeneic stem cell transplantation for acute myeloid leukemia. Biomed Pap Med Fac Univ Palacky Olomouc Czech Repub 155:327-332.

25. Lioure B, MC Bene, A Pigneux, A Huynh, P Chevallier, N Fegueux, D Blaise, B Witz, M Delain, et al. (2012). Early matched sibling hematopoietic cell transplantation for adult AML in first remission using an age-adapted strategy: longterm results of a prospective GOELAMS study. Blood 119:2943-2948.

26. Martino R, D Valcarcel, S Brunet, A Sureda and J Sierra. (2008). Comparable non-relapse mortality and survival after HLA-identical sibling blood stem cell transplantation with reduced or conventional-intensity preparative regimens for high-risk myelodysplasia or acute myeloid leukemia in first remission. Bone Marrow Transplant 41: 33-38.
27. Bacigalupo A. (2004). Third EBMT/AMGEN Workshop on reduced-intensity conditioning allogeneic haemopoietic stem cell transplants (RIC-HSCT), and panel consensus. Bone Marrow Transplant 33:691-696.

28. Giralt S, K Ballen, D Rizzo, A Bacigalupo, M Horowitz, M Pasquini and B Sandmaier. (2009). Reduced-intensity conditioning regimen workshop: defining the dose spectrum. Report of a workshop convened by the center for international blood and marrow transplant research. Biol Blood Marrow Transplant 15:367-369.

29. Tanaka J, H Kanamori, S Nishiwaki, K Ohashi, S Taniguchi, T Eto, H Nakamae, K Minagawa, K Miyamura, et al. (2013). Reduced-intensity vs myeloablative conditioning allogeneic hematopoietic SCT for patients aged over 45 years with ALL in remission: a study from the Adult ALL Working Group of the Japan Society for Hematopoietic Cell Transplantation (JSHCT). Bone Marrow Transplant 48:1389-1394.

30. Bachanova V, DI Marks, MJ Zhang, H Wang, M de Lima, MD Aljurf, M Arellano, AS Artz, U Bacher, et al. (2013). $\mathrm{Ph}+\mathrm{ALL}$ patients in first complete remission have similar survival after reduced intensity and myeloablative allogeneic transplantation: Impact of tyrosine kinase inhibitor and minimal residual disease. Leukemia 28:658665.

31. Terwey TH, A Vega-Ruiz, PG Hemmati, P Martus, E Dietz, P le Coutre, G Massenkeil, B Dorken and R Arnold. (2012). NIH-defined graft-versus-host disease after reduced intensity or myeloablative conditioning in patients with acute myeloid leukemia. Leukemia 26:536-542.

32. Parker JE, T Shafi, A Pagliuca, A Mijovic, S Devereux, M Potter, HG Prentice, M Garg, JA Yin, et al. (2002). Allogeneic stem cell transplantation in the myelodysplastic syndromes: interim results of outcome following reducedintensity conditioning compared with standard preparative regimens. Br J Haematol 119:144-154.

33. Gyurkocza B, R Storb, BE Storer, TR Chauncey, T Lange, JA Shizuru, AA Langston, MA Pulsipher, CN Bredeson, et al. (2010). Nonmyeloablative allogeneic hematopoietic cell transplantation in patients with acute myeloid leukemia. J Clin Oncol 28:2859-2867.

34. McSweeney PA, D Niederwieser, JA Shizuru, BM Sandmaier, AJ Molina, DG Maloney, TR Chauncey, TA Gooley, U Hegenbart, et al. (2001). Hematopoietic cell transplantation in older patients with hematologic malignancies: replacing high-dose cytotoxic therapy with graftversus-tumor effects. Blood 97:3390-3400.

35. Marks R, K Potthoff, J Hahn, G Ihorst, H Bertz, A Spyridonidis, E Holler and JM Finke. (2008). Reduced-toxicity conditioning with fludarabine, BCNU, and melphalan in allogeneic hematopoietic cell transplantation: particular activity against advanced hematologic malignancies. Blood 112:415-425.

36. Alyea EP, HT Kim, V Ho, C Cutler, DJ DeAngelo, R Stone, J Ritz, JH Antin and RJ Soiffer. (2006). Impact of conditioning regimen intensity on outcome of allogeneic hematopoietic cell transplantation for advanced acute myelogenous leukemia and myelodysplastic syndrome. Biol Blood Marrow Transplant 12:1047-1055.

37. Nishiwaki S, Y Inamoto, M Imamura, H Tsurumi, K Hatanaka, K Kawa, R Suzuki and K Miyamura. (2011). Reduced-intensity versus conventional myeloablative conditioning for patients with Philadelphia chromosome- 
negative acute lymphoblastic leukemia in complete remission. Blood 117:3698-3699.

38. Ringden O, M Labopin, G Ehninger, D Niederwieser, R Olsson, N Basara, J Finke, R Schwerdtfeger, M Eder, et al. (2009). Reduced intensity conditioning compared with myeloablative conditioning using unrelated donor transplants in patients with acute myeloid leukemia. J Clin Oncol 27:4570-4577.

39. Sayer HG, M Kroger, J Beyer, M Kiehl, SA Klein, K Schaefer-Eckart, R Schwerdtfeger, W Siegert, V Runde, et al. (2003). Reduced intensity conditioning for allogeneic hematopoietic stem cell transplantation in patients with acute myeloid leukemia: disease status by marrow blasts is the strongest prognostic factor. Bone Marrow Transplant 31:1089-1095.

40. Wahid SF. (2013). Indications and outcomes of reducedtoxicity hematopoietic stem cell transplantation in adult patients with hematological malignancies. Int $\mathrm{J}$ Hematol 97:581-598.

41. Hill GR and JL Ferrara. (2000). The primacy of the gastrointestinal tract as a target organ of acute graft-versus-host disease: rationale for the use of cytokine shields in allogeneic bone marrow transplantation. Blood 95:2754-2759.

42. van Besien K, A Dew, S Lin, L Joseph, LA Godley, RA Larson, T Odenike, E Rich, W Stock, A Wickrema and AS Artz. (2009). Patterns and kinetics of T-cell chimerism after allo transplant with alemtuzumab-based conditioning: mixed chimerism protects from GVHD, but does not portend disease recurrence. Leuk Lymphoma 50:1809-1817.

43. Mattsson J, M Uzunel, $M$ Remberger and $O$ Ringden. (2001). T cell mixed chimerism is significantly correlated to a decreased risk of acute graft-versus-host disease after allogeneic stem cell transplantation. Transplantation 71: 433-439.

44. Couriel DR, RM Saliba, S Giralt, I Khouri, B Andersson, M de Lima, C Hosing, P Anderlini, M Donato, et al. (2004). Acute and chronic graft-versus-host disease after ablative and nonmyeloablative conditioning for allogeneic hematopoietic transplantation. Biol Blood Marrow Transplant 10:178-185.

45. Clift RA, CD Buckner, FR Appelbaum, E Bryant, SI Bearman, FB Petersen, LD Fisher, C Anasetti, P Beatty, WI Bensinger, et al. (1991). Allogeneic marrow transplantation in patients with chronic myeloid leukemia in the chronic phase: a randomized trial of two irradiation regimens. Blood 77:1660-1665.

46. Childs R, E Clave, N Contentin, D Jayasekera, N Hensel, S Leitman, EJ Read, C Carter, E Bahceci, NS Young and AJ Barrett. (1999). Engraftment kinetics after nonmyeloablative allogeneic peripheral blood stem cell transplantation: full donor T-cell chimerism precedes alloimmune responses. Blood 94:3234-3241.

47. Carvallo C, N Geller, R Kurlander, R Srinivasan, O Mena, T Igarashi, LM Griffith, WM Linehan and RW Childs. (2004). Prior chemotherapy and allograft CD34+ dose impact donor engraftment following nonmyeloablative allogeneic stem cell transplantation in patients with solid tumors. Blood 103:1560-1563.

48. Baron F, M Labopin, D Niederwieser, S Vigouroux, JJ Cornelissen, C Malm, LL Vindelov, D Blaise, JJ Janssen, et al. (2012). Impact of graft-versus-host disease after reduced-intensity conditioning allogeneic stem cell transplantation for acute myeloid leukemia: a report from the
Acute Leukemia Working Party of the European group for blood and marrow transplantation. Leukemia 26:24622468.

49. Baron F, MB Maris, BM Sandmaier, BE Storer, M Sorror, R Diaconescu, AE Woolfrey, TR Chauncey, ME Flowers, et al. (2005). Graft-versus-tumor effects after allogeneic hematopoietic cell transplantation with nonmyeloablative conditioning. J Clin Oncol 23:1993-2003.

50. Graef T, M Vaupel, R Fenk, L Ruf, F Zohren, U Germing, R Haas and G Kobbe. (2007). Prognostic factors for patients with acute myeloid leukaemia or high-risk myelodysplastic syndromes undergoing myeloablative or nonmyeloablative allogeneic blood stem cell transplantation. Hematol Oncol 25:170-177.

51. Flynn CM, B Hirsch, T Defor, JN Barker, JS Miller, JE Wagner, BR Blazar, LJ Burns, ML Macmillan, M Arora and D Weisdorf. (2007). Reduced intensity compared with high dose conditioning for allotransplantation in acute myeloid leukemia and myelodysplastic syndrome: a comparative clinical analysis. Am J Hematol 82:867-872.

52. Scott BL, BM Sandmaier, B Storer, MB Maris, ML Sorror, DG Maloney, TR Chauncey, R Storb and HJ Deeg. (2006). Myeloablative vs nonmyeloablative allogeneic transplantation for patients with myelodysplastic syndrome or acute myelogenous leukemia with multilineage dysplasia: a retrospective analysis. Leukemia 20:128-135.

53. Massenkeil G, M Nagy, S Neuburger, I Tamm, C Lutz, P le Coutre, O Rosen, KD Wernecke, B Dorken and R Arnold. (2005). Survival after reduced-intensity conditioning is not inferior to standard high-dose conditioning before allogeneic haematopoietic cell transplantation in acute leukaemias. Bone Marrow Transplant 36:683-689.

54. Sorror ML, BM Sandmaier, BE Storer, MB Maris, F Baron, DG Maloney, BL Scott, HJ Deeg, FR Appelbaum and R Storb. (2007). Comorbidity and disease status based risk stratification of outcomes among patients with acute myeloid leukemia or myelodysplasia receiving allogeneic hematopoietic cell transplantation. J Clin Oncol 25:42464254.

55. Todisco E, F Ciceri, E Oldani, C Boschini, C Mico, MT Vanlint, I Donnini, F Patriarca, PE Alessandrino, et al. (2013). The CIBMTR score predicts survival of AML patients undergoing allogeneic transplantation with active disease after a myeloablative or reduced intensity conditioning: a retrospective analysis of the Gruppo Italiano Trapianto Di Midollo Osseo. Leukemia 27:2086-2091.

56. Lim Z, R Brand, R Martino, A van Biezen, J Finke, A Bacigalupo, D Beelen, A Devergie, E Alessandrino, et al. (2010). Allogeneic hematopoietic stem-cell transplantation for patients 50 years or older with myelodysplastic syndromes or secondary acute myeloid leukemia. J Clin Oncol 28:405-411.

57. Takasaki H, M Tanaka, T Tachibana, A Numata, K Fujimaki, R Sakai, S Fujisawa, N Tomita, H Fujita, et al. (2012). Prognostic factors in patients aged 50 years or older undergoing allogeneic hematopoietic stem cell transplantation for hematologic malignancy. Int J Hematol 95:291-298.

58. Khabori MA, M El-Emary, W Xu, G Guyatt, A Galal, J Kuruvilla, J Lipton, H Messner and V Gupta. (2011). Impact of intensity of conditioning therapy in patients aged 40-60 years with AML/myelodysplastic syndrome undergoing allogeneic transplantation. Bone Marrow Transplant 46:516-522. 
59. Martino R, L de Wreede, M Fiocco, A van Biezen, PA von dem Borne, RM Hamladji, L Volin, M Bornhauser, M Robin, et al. (2013). Comparison of conditioning regimens of various intensities for allogeneic hematopoietic SCT using HLA-identical sibling donors in AML and MDS with $<10 \%$ BM blasts: a report from EBMT. Bone Marrow Transplant 48:761-770.

60. Foran JM, SZ Pavletic, BR Logan, MA Agovi-Johnson, WS Perez, BJ Bolwell, M Bornhauser, CN Bredeson, MS Cairo, et al. (2013). Unrelated donor allogeneic transplantation after failure of autologous transplantation for acute myelogenous leukemia: a study from the center for international blood and marrow transplantation research. Biol Blood Marrow Transplant 19:1102-1108.
Address correspondence to: Prof. S. Fadilah Abdul Wahid Cell Therapy Center Faculty of Medicine Universiti Kebangsaan Malaysia Medical Centre Kuala Lumpur 56000

Malaysia

E-mail: sfadilah@ppukm.ukm.edu.my

Received for publication March 9, 2014

Accepted after revision July 22, 2014

Prepublished on Liebert Instant Online July 29, 2014 